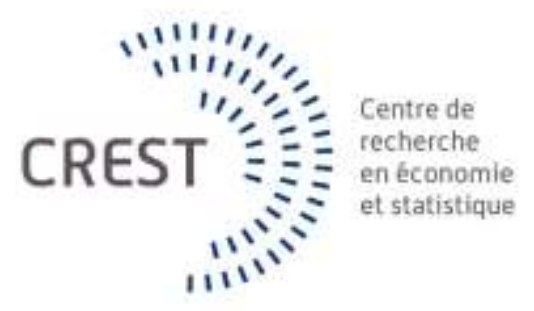

Série des Documents de Travail

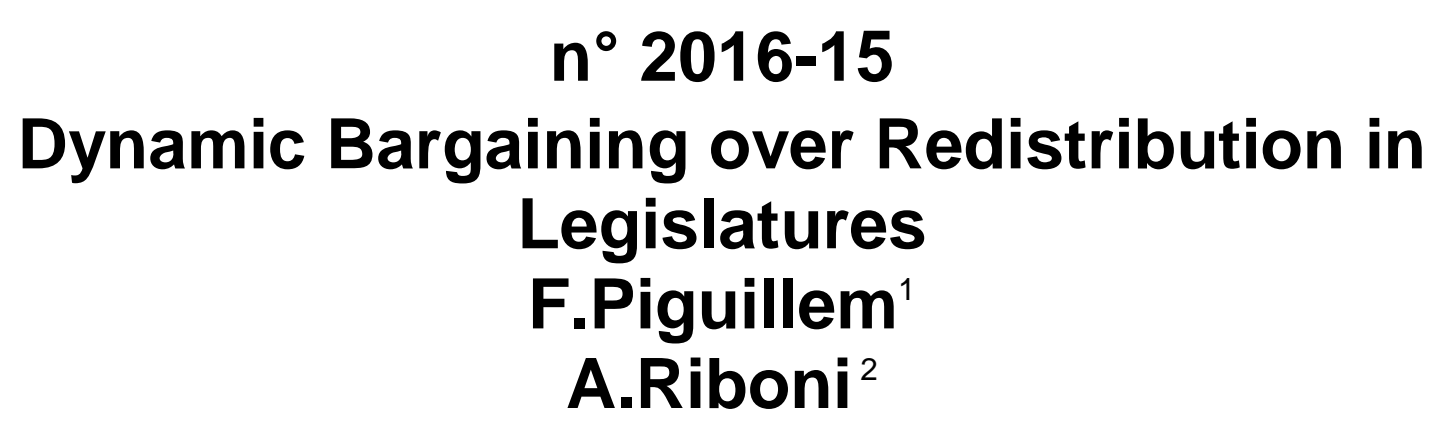

Les documents de travail ne reflètent pas la position du CREST et n'engagent que leurs auteurs. Working papers do not reflect the position of CREST but only the views of the authors.

\footnotetext{
${ }^{1}$ Einaudi Institute for Economics and Finance (EIEF). E-mail: facundo.piguillem@gmail.com

${ }^{2}$ Ecole Polytechnique. E-mail: alessandro.riboni@polytechnique.edu
} 


\title{
Dynamic Bargaining over Redistribution in Legislatures*
}

\author{
FACUndo Piguillem ${ }^{\dagger}$ \\ Alessandro RiBOni ${ }^{\ddagger}$
}

January 2016

\begin{abstract}
In modern democracies, public policies are negotiated by elected policymakers. When they agree to replace the current status quo, the approved policy becomes the status quo in the next period. Yet, these two ingredients, bargaining and endogenous status quo, are absent from most macroeconomic models. We revisit the classical capital taxation problem including both ingredients. We analyze a growth model where agents are heterogenous in wealth. We find that legislators may avoid high taxes, because doing so may improve the bargaining power of "poorer" legislators in future negotiations. Equilibrium capital taxes are between 12\% and 55\%, depending on the calibration. We also find that a status quo bias could lead to growth cycles: decades with low taxes and growing capital are followed by decades with high taxes and decreasing capital (and vice versa).
\end{abstract}

JEL Classification: E60, H00.

Keywords: Redistribution, Time Consistency, Capital Taxes, Legislative Bargaining, Markovperfect Equilibria, Political Growth Cycles.

* We greatly benefited from comments by Marco Bassetto, Davide Debortoli, Mike Golosov, Roger Lagunoff (NBER discussant), Jinhui Bai, Bard Harstad, Pierre Yared, Nicholas Trachter and participants at the Princeton Conference on Political Economy, NBER Summer meetings (Political Economy Public Finance Workshop), SED Meetings in Ghent, ESEM Meetings in Oslo, Lacea-Lames Meetings in Santiago, CPEG Meetings, City University of Hong Kong, École Polytechnique, EIEF, EUI, LUISS, Mannheim, ParisDauphine, Sciences-Po, CEMFI and CERGE-EI.

$\dagger$ Einaudi Institute for Economics and Finance (EIEF)

$\ddagger$ Ecole Polytechnique 


\section{Introduction}

In modern democracies, public choices are usually the result of negotiations among elected policymakers. The recent intense negotiations over the US and EU budgets are clear examples of the importance of post-election bargaining. Budget negotiations also point to the key role played by the status quo, the endogenous default option in case of disagreement. Motivated by these facts, we explicitly model legislative bargaining and analyze the strategic role played by the status quo. Thus, we depart from most of the macro-political economics literature, which mainly focuses on median-voter equilibria or bargaining with an exogenous status quo.

Legislative bargaining could have many interesting implications for fiscal policy, but in this paper we focus on the "stickiness" implied by the political process. Policies can be sticky (or persistent) for two reasons: political gridlock and gradualism. The first refers to the absence of policy changes, while the second to the fact that changes may happen but new policies are close to the previous one. Persistence creates a link across periods. When politicians have time inconsistency problems, persistence serves as a commitment device: it provides "loose commitment".

The macro-political economics literature has found the striking result that Markovian equilbria in "standard models" generate confiscatory levels of capital taxation. Thus, to obtain empirically reasonable levels of taxation, some form of loose commitment is exogenously assumed, such as choosing a policy once-and-for-all (Alesina and Rodrik, 1994), an implementation lag (Krusell and Rios-Rull, 1999), and an exogenous persistence (Bénabou and Ok, 2001 and Debortoli and Nunes, 2010). In general, the rationale for these types of assumptions is the existence of political frictions.

Our main contribution lies in endogenizing the political friction and understanding the consequences of alternative institutional features. We show that the endogenous persistence induced by bargaining generates empirically relevant levels of capital taxation, between $25 \%$ and $50 \%$. It also leads to features which are not present in the standard median voter model, such as political growth cycles. Finally, endogenizing political frictions allows us to understand how changes in the environment might amplify the political divide, capturing the view that political polarization might be a process that feeds upon itself.

This paper studies sequential bargaining over redistribution in the context of a standard Neoclassical growth model. The economy is populated by: (i) consumers, (ii) a competitive 
firm, and (iii) legislators who periodically vote to determine the current capital tax rate. Tax revenues are used to distribute a common lump-sum transfer to all consumers. Consumers as well as legislators differ with respect to their wealth. Legislators vote in order to maximize the utility of the consumers with their same level of wealth. Since taxes are proportional to capital income, capital taxation is a way of redistributing from consumers with high wealth to consumers with low wealth.

Following Romer and Rosenthal (1978) and Baron and Ferejohn (1989), we model the political process as an agenda-setting game. ${ }^{1}$ In each period one member of the legislature (the agenda setter) is randomly selected to make a take-it-or-leave-it proposal. Subsequently, the legislature decides whether to accept the new policy or to maintain the status quo. If the proposal is rejected, the tax from the previous period (the status quo) is kept in place for one more period. If it is accepted, which happens with a probability equal to the measure of legislators favoring the proposal, the tax is implemented and the current policy becomes the default option in the next legislative session. Thus, since it defines the legislators' reservation utility, the status quo becomes a payoff-relevant state: forward-looking legislators must internalize the consequences of the current decision on future legislative sessions via its effect on the status quo.

A key feature of the environment is that most politicians have endogenous time-inconsistent preferences over taxes and redistribution. Under commitment, legislators with pre-tax income below the mean (the vast majority) would select maximum taxes in the current period (to maximize redistribution) and lower taxes in the future (to minimize distortions on savings decisions). However, once capital has been accumulated, taxing capital is no longer distortive. In the absence of commitment, legislators are thus tempted to raise capital taxes up to the maximum possible level in order to redistribute: the poorer the legislator, the higher the temptation.

We solve for Markov-perfect equilibria of the dynamic game between legislators. Our results show that legislative bargaining with an endogenous status quo strongly reduces policymakers' temptation to raise taxes ex-post. The economic mechanism which disciplines

\footnotetext{
${ }^{1}$ The legislative bargaining approach is widely adopted in political economy, but few papers have used it in the context of a standard macro model. For macro applications of the median voter see Meltzer and Richard (1981), Alesina and Rodrik (1994), Persson and Tabellini (1994a), Krusell and Rios-Rull (1999), Azzimonti et al. (2006), and Corbae et al. (2009).
} 
legislators operates through two channels. First, legislative bargaining generates endogenous persistence. Policy changes may be rejected in equilibrium because some legislators may prefer the status quo policy to alternative proposed taxes. When the status quo is endogenous, legislators internalize that high taxes, by changing the future status quo, will raise the bargaining power of poorer legislators and thus stay in place for more than one period. When policy gridlock is expected in the future, legislators have to balance their present desire for high redistribution with their distaste for long-term savings distortions. Second, small departures from the status quo are more likely to be approved by the legislature. Gradualism in policy-making implies that policy proposals are monotone increasing in the status quo. Since the probability of future high-tax proposals is increasing in the current tax, keeping a low status quo is a way to strategically manipulate (namely, improve) equilibrium proposals of future agenda setters. ${ }^{2}$

We numerically compute policy proposals and acceptance strategies. When calibrating the legislators' wealth distribution we have to take a stance on legislators' objectives. On the one hand, if legislators were fully benevolent they should act as representatives of the population that elected them. In this case, the appropriate distribution would be the distribution of net worth in the whole population. On the other hand, if we believe that legislators are completely self-interested we should calibrate the distribution to match the distribution of wealth among legislators. We perform both exercises with data for the U.S economy and the U.S. Congress in 2007. Under the first assumption we find that average taxes are around 50\%, while under the second assumption taxes average 25\%. These taxes are well below the ones usually obtained by Markov equilibria where, as in this paper, decision makers sequentially choose the current capital tax. We do so, without appealing to exogenous sources of loose commitment, but just modelling a key feature of legislative bargaining.

After computing the politico-economic equilibrium, we analyze how taxation and the size of government are affected by changes in the political and institutional environment.

When looking at the outcome paths, we show that the endogeneity of the status quo induces politically driven growth cycles. When the stock of capital is high, the inefficiency cost of high taxes is small because even without further capital accumulation, output would

\footnotetext{
${ }^{2}$ The disciplinary role of gridlock has been analyzed in Piguillem and Riboni (2015), however gradualism is not present in their paper. See Section 2 for a discussion.
} 
stay high. Moreover, the gains from redistribution are larger since the pie is bigger. The opposite is true when the stock of capital is low. Thus, periods with low capital tend to be associated with low taxes. Since taxes are persistent, observing low taxes encourages consumers to save. However, as capital accumulates, legislators become increasingly tempted to set higher taxes. Eventually, a tax hike will pass, which leads to low investment and negative capital accumulation, and the cycle begins again.

Finally, we find that changes of wealth inequality among legislators lead to "polarization" of political positions, beyond those implied by the change of inequality alone. Consider a distributional shift consisting of increasing the mass of rich legislators. This generates two effects. First, rich legislators gain less from redistribution, which implies that low taxes are proposed and accepted more often. But, second, there is an indirect effect through equilibrium strategies. Since more legislators favor low taxes, the persistence of high taxes diminishes, and so does the marginal benefit of keeping taxes low to constrain future legislators. Relatively poor legislators have an incentive to free-ride on others' responsibility, and consequently, they favor higher taxes than the ones they had previously supported. With poor legislators becoming more pro-taxes, relatively richer legislators have stronger incentives to favor low taxes, so that political polarization is amplified.

In Section 3.2, we describe the competitive equilibrium given an arbitrary stochastic process for policies. In Section 3.3, we describe the political game. In Section 4, we present a simple example to help build intuition. In Section 5, we present the numerical solutions. Section 6 concludes.

\section{Literature Review}

There are two main approaches to study capital taxation: the traditional normative approach taken by the literature on optimal capital taxation and the positive approach, used in, for example, the recent macro-dynamic-political economy literature. The two approaches lead to different implications. The normative approach prescribes that, in a wide range of environments, the tax on capital should be zero in the long-run. ${ }^{3}$ Conversely, the positive literature has shown that, without assuming either ad-hoc constraints or history-dependent strategies,

\footnotetext{
${ }^{3}$ This is the classical result under commitment of Chamley (1986) and Judd (1985). Positive capital taxes are obtained in Aiyagari (1995), Conesa et al. (2009), Straub and Werning (2014), and Piketty and Saez (2012).
} 
the tax on capital is very close to $100 \%$. For instance, in Klein et al. (2008) and Azzimonti et al. (2006) the equilibrium capital taxes without commitment are extremely high (81\% and $100 \%$, respectively). To avoid this outcome, the typical constraint assumed in the literature is that policymakers can choose the tax for the next period, not the current one. ${ }^{4}$

The positive literature using computational methods was pioneered by the work of Krusell et al. (1997), who propose a notion of politico-economic equilibrium where political outcomes chosen by a forward looking median voter must be consistent with a sequential equilibrium of the competitive economy. Krusell and Rios-Rull (1999) consider a calibrated version of the Solow model. In contrast to this paper, they assume that the median voter theorem holds and agents vote on the tax in the next period. Their findings show that the size of transfers predicted by the model is close to that in the US data. More recently, Corbae et al. (2009) consider a setting in which individuals have uninsurable idiosyncratic labor efficiency shocks and conclude that in the US, the median model would predict an excessively large increase of redistribution following the increase in wage inequality in the 80s and 90s. Bachmann and Bai (2011) study the comovement of government purchases with macroeconomic fluctuations under two politico-economic equilibria: probabilistic voting and wealth-weighted majority voting. Bassetto (2008) is one of the few papers that incorporates a bargaining process into a standard macro model. He considers an economy where two overlapping generations Nash-bargain over tax rates, transfers, and government spending. Aguiar and Amador (2011) consider a growth model where incumbent governments prefer consumption to occur when they are in power and, thus, have an incentive to expropriate capital. They focus on selfenforcing equilibria supported by threat of switching to the autarky. ${ }^{5}$

Alesina and Tabellini (1990), Persson and Svensson (1989), Amador (2003), Azzimonti (2011) and Azzimonti and Talbert (2013), show that governments affect the policy carried out by future governments by manipulating their successors' constraints via some state variable (e.g., debt or investment). In our setting, besides capital, the dynamic linkage across periods is created by the status quo. Another key difference from these papers is that they assume

\footnotetext{
${ }^{4}$ See for instance Persson and Tabellini (1994a), Bénabou (1996), Krusell and Rios-Rull (1999), Klein and Rios-Rull (2003), and Corbae et al. (2009). One exception is Martin (2010), who allows for endogenous capacity utilization. Alternatively, low capital taxes may be sustained thanks to reputation mechanisms (see Chari and Kehoe, 1990, and Phelan and Stacchetti, 2001).

${ }^{5}$ Other contributions to the recent dynamic political economy literature include the electoral accountability models by Acemoglu at al. (2008) and Yared (2010).
} 
that the winning party is a policy dictator (no checks and balances) and, consequently, there is no need of negotiating. Their main result is that alternating power leads to strategic manipulation and generates inefficiency (such as, excessive debt or low investment). Notice that in contrast to this literature, political turnover is overall beneficial in our model. On the one hand, it increases policy variability. But on the other hand, the risk of losing power gives current policymakers the incentive to strategically maintain a low status quo. ${ }^{6}$

The legislative bargaining approach has been adopted in Battaglini and Coate (2007, 2008) and Battaglini et al. (2013). Battaglini and Coate (2008) analyze a legislature of representatives making decisions about pork barrel spending, public good, and debt. Their goal is to analyze how policies respond to shocks in public spending needs and to characterize how public debt evolves over time. ${ }^{7}$ Besides considering different subject matters, their setting differs from ours along two other dimensions. First, they abstract from capital and they assume that the default option in case of disagreement is exogenous. In their model the dynamic linkage across periods is given by the level of public debt. Second, we study a different source of disagreement between current and future governments. In Battaglini and Coate $(2007,2008)$ current governments disagree with their successors on how to allocate pork. In our model disagreement between current and future governments arises for two different reasons. First, given that the supply of future capital is elastic, today's government would like future governments to choose lower capital taxes. Second, current and future governments disagree because they represent constituencies with different wealth. Riboni (2010) builds a dynamic agenda setting model in a stylized Barro-Gordon economy in order to study monetary policymaking. He shows that the endogenous status quo reduces the inflation bias and finds conditions under which monetary policy committees perform better than single central bankers. Persson et al. $(1997,2000)$ analyze alternative legislative-bargaining games in order to study the size and composition of government spending under presidential and parliamentary regimes.

Finally, this paper is related to the growing literature on legislative bargaining with an endogenous status quo. This literature generally finds that when legislators have concave utilities having an endogenous status quo improves welfare by reducing policy variability. This result was first obtained by Baron (1996), who finds that policy converges to the alternative

\footnotetext{
${ }^{6}$ The beneficial effect of political turnover has been pointed out in Acemoglu et al. (2011).

${ }^{7}$ Azzimonti et al. (2011) analyze the impact of a balanced-budget rule.
} 
preferred by the median legislator. By means of numerical simulation, Baron and Herron (2003) obtain a similar result in a two-dimensional setting. Duggan and Kalandrakis (2011) also argue that when players are sufficiently patient, the endogeneity of the status quo induces core convergence. ${ }^{8}$ Bowen and Zahran (2012) study a divide a dollar game with endogenous default and shows that legislators have an incentive to reach a compromise. When legislators are risk-neutral, this result does not hold anymore. Kalandrakis (2004) considers a dynamic divide-a-dollar game and shows that in each period the agenda setter extracts all surplus. As a result, he obtains great variance of policies over time. Bowen et al. (2014) study public good provision and argue that when the status quo is endogenous, current governments are able to insure themselves against power switches. More specifically, when parties alternate in power, bargaining with an endogenous status quo provides payoff smoothing, which is beneficial to both parties. As opposed to all papers in this literature we consider time inconsistent preferences. ${ }^{9}$ We emphasize that in this paper the endogenous status quo is beneficial for a different reason: because it serves a disciplinary role. In Bowen et al. (2014), each party would benefit if it stayed in power in all periods and if it could choose policies without the other party's approval. In our model, instead, this would lead to a bad policy outcome with very high taxes and low savings.

In Piguillem and Riboni (2015) we consider a model without capital accumulation and linear utilities. As in this paper, we show that the status quo serves a disciplinary role. The contribution of Piguillem and Riboni (2015) is to analyze, in the context of a tractable model with only two policy choices, the strategic interactions among current and future decisions by legislators who have an exogenous present-bias for current spending. This model is different along many dimensions. In Piguillem and Riboni (2015) commitment problems are assumed in the politicians' preferences. In this paper they arise endogenously in the context of a general equilibrium growth model and depend on the economic and institutional environment. Moreover, in Piguillem and Riboni (2015), equilibrium strategies do not depend on the status quo, while in this paper they are monotone increasing in the status quo. The

\footnotetext{
${ }^{8}$ Among other papers in the endogenous status-quo literature, Bernheim et al. (2006), and Diermeier and Fong (2010), Riboni and Ruge-Murcia (2008), Nunnari (2012), Baron and Bowen (2013), Bowen et al. (2014), Dziuda and Loeper (2015), and Anesi and Seidmann (2015).

${ }^{9}$ Recent papers introduce self-control problems into political economy models. In Bisin et al. (2015) and Lizzeri and Yariv (2015), voters are time inconsistent and politicians may exploit their biases to win the election.
} 
result that small departures from the status quo are more likely to be approved (gradualism) will introduce a second disciplinary channel.

\section{The Model}

\subsection{Overview}

The model economy includes three types of decision makers: consumers who consume and invest, a firm that rents inputs and produces the only good in the economy, and legislators who decide the tax on capital in every period. It is important to keep in mind the general timing of events (see Figure 1). At the beginning of each period $t$, the firm makes its production decision, and then legislators meet and bargain over the current tax $\tau_{t}$. Finally, knowing the political outcome, consumers make their consumption and saving decisions.

\section{Figure 1}

Timing of Events within a Period

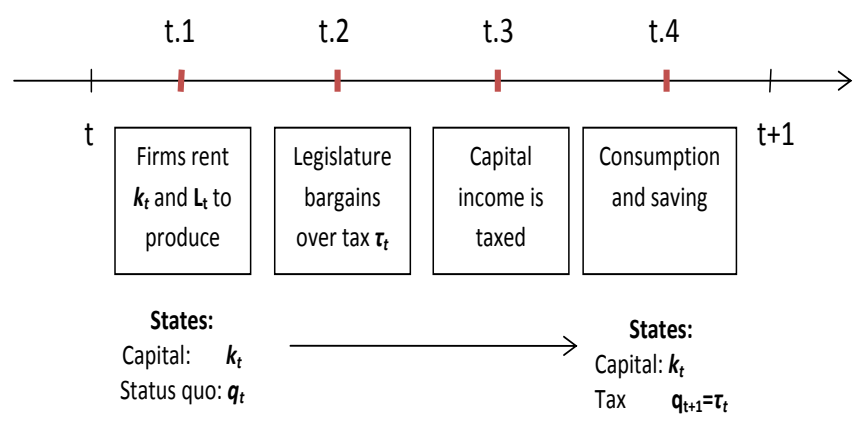

Throughout, we focus on Markov Perfect equilibria where strategies depend on the payoffrelevant state variable. At time $t$, the state variable in the political game is given by the predetermined level of capital $k_{t}$ and the status quo level of taxation $q_{t}$, where $q_{t}=\tau_{t-1}$. Any equilibrium of the political game can be represented by a stochastic Markov process with $\Gamma\left(\tau_{t} \mid q_{t}, k_{t}\right)$ determining the probability of a tax rate $\tau_{t}$ given a capital stock $k_{t}$ and status quo $q_{t}$.

Consumers at time $t$ make savings decisions after observing the political outcome $\tau_{t}$. Therefore, the state variable in the consumers' problem is given by the current level of taxation (the status quo for next period) and the current level of capital $k_{t}$. Given initial capital, any competitive equilibrium can be summarized by the law of motion of aggregate capital, denoted by $G\left(k_{t}, \tau_{t}\right)$. 


\subsection{The Economy}

Time is infinite and indexed by $t=0,1, \ldots$. There is a continuum of consumers of measure one. Consumers are heterogenous in their initial wealth (capital). Consumers of type $i$ are initially endowed with $k_{0}^{i}=\theta^{i} k_{0}$ units of capital, where $\theta^{i} \in \Theta$ denotes their wealth share at time 0 , and $k_{0}$ is the initial aggregate (and mean) stock of capital. Let $\tilde{\mu}_{t}\left(k_{t}\right)$ be the measure of consumers over holdings of capital $k_{t}$ and let $\mu\left(\theta^{i}\right)$ be the measure of shares $\theta^{i}$. Notice that $E\left(\theta^{i}\right)=1$.

Consumers are endowed with one unit of labor, which is inelastically supplied. Their total income is the sum of real wage $w_{t}$, a lump-sum transfer from the government $T_{t}$, and the after tax return on capital holdings $k_{t}^{i}$. Markets are incomplete in the sense that agents can only transfer resources across periods through capital, a non state-contingent asset. The proportional tax on the returns from capital holdings is $\tau_{t}$. Therefore, when choosing allocations consumers are subject to the following budget constraints:

$$
\begin{array}{r}
c_{t}^{i}+k_{t+1}^{i}=w_{t}+T_{t}+R_{t} k_{t}^{i} \\
k_{t+1}^{i} \geq 0, \quad \forall t
\end{array}
$$

where

$$
R_{t}=1+\left(r_{t}-\delta\right)\left(1-\tau_{t}\right),
$$

is the gross return on capital after taxes and $r_{t}$ is the before-tax return on capital.

At time $t$ consumer $i$ orders stochastic sequences of consumption according to the expected utility that they deliver:

$$
E_{t}\left(\sum_{j=t}^{\infty} \beta^{j-t} u\left(c_{j}^{i}\right)\right),
$$

where $E_{t}($.$) denotes the expectation conditioned on time t$ information, $\beta \in[0,1)$ is the discount factor and per-period utility is of the constant risk relative aversion (CRRA) type. As will be explained in Section 3.3, the only source of uncertainty in this economy comes from the political process: it concerns the identity of the executive and whether or not the executive's proposal is accepted.

There is a single firm that rents capital and labor services to produce the unique con- 
sumption good. Production combines labor with capital using the following constant-returnsto-scale production function:

$$
f\left(k_{t}\right)=k_{t}^{\alpha}
$$

Since there is perfect competition, the firm chooses capital and labor services to satisfy the following conditions:

$$
\begin{gathered}
r_{t}=f^{\prime}\left(k_{t}\right) \\
w_{t}=f\left(k_{t}\right)-k_{t} f^{\prime}\left(k_{t}\right)
\end{gathered}
$$

The government does not issue debt or consume, so the government budget's constraint is:

$$
\tau_{t}\left(r_{t}-\delta\right) k_{t}=T_{t} \quad \forall t
$$

Given $\tilde{\mu}_{0}$, a law of motion for the distribution of capital $G\left(\tilde{\mu}_{t}, \tau_{t}\right)$, and an arbitrary Markov process for taxes, $\Gamma\left(\tau_{t} \mid \tau_{t-1}, \tilde{\mu}_{t}\right)$, it is possible to generate a stochastic path for any $\tau_{t}$ and wealth distribution. We now define the competitive equilibrium of our economy for a given sequence of policies.

Competitive Equilibrium Definition: Let $\Gamma\left(\tau_{t} \mid \tau_{t-1}, \tilde{\mu}_{t}\right)$ and the initial distribution of wealth be given. A Competitive Equilibrium is a stochastic sequence of fiscal policies $\left\{T_{t}, \tau_{t}\right\}_{t=0}^{\infty}$ allocations $\left\{c_{t}^{i}, k_{t}^{i}\right\}_{t=0}^{\infty}$ for all $\theta^{i}$, prices $\left\{w_{t}, r_{t}\right\}_{t=0}^{\infty}$ and a law of motion $G\left(\tilde{\mu}_{t}, \tau_{t}\right)$ for the distribution of wealth such that:

1) Given prices, $G\left(\tilde{\mu}_{t}, \tau_{t}\right)$ and $\Gamma\left(\tau_{t} \mid \tau_{t-1}, \tilde{\mu}_{t}\right)$, the allocation for every consumer $\theta^{i}$ maximizes (3) subject to (1).

2) Factor prices satisfy the firm's first order conditions (5) and (6).

3) Given prices and aggregate allocations, the sequence of fiscal policies is generated by $\Gamma\left(\tau_{t} \mid \tau_{t-1}, \tilde{\mu}_{t}\right)$ and the government's budget constraint.

4) Markets clear:

$$
c_{t}+k_{t+1}-(1-\delta) k_{t}=f\left(k_{t}\right)
$$

where

$$
c_{t}=\int_{\Theta} \mu\left(\theta^{i}\right) c_{t}^{i} d \theta^{i} \quad \text { and } \quad k_{t+1}=\int_{\Theta} \mu\left(\theta^{i}\right) k_{t+1}^{i} d \theta^{i}
$$


5) $\tilde{\mu}_{t+1}=G\left(\tilde{\mu}_{t}, \tau_{t}\right)$ is generated by agents' optimal decisions.

Using the government's budget (7) and equilibrium prices in the consumer's budget constraint, in equilibrium (1) can be written as:

$$
c_{t}^{i}+k_{t+1}^{i}=f\left(k_{t}\right)+(1-\delta) k_{t}+\left(\theta_{t}^{i}-1\right)\left[1+\left(1-\tau_{t}\right)\left(f^{\prime}\left(k_{t}\right)-\delta\right)\right] k_{t},
$$

where $\theta_{t}^{i}$ denotes the wealth-share of consumer $i$ at time $t$. The right-hand side of (9) is consumer $i$ 's cash on hand at period $t$, which sheds lights on the redistributional effects of capital taxation. Agents with $\theta_{t}^{i}<1$ gain with positive taxes -the smaller $\theta_{t}^{i}$, the larger the gain. Agents with $\theta_{t}^{i}>1$ are worse off when capital is taxed -the larger $\theta_{t}^{i}$, the larger their loss.

If a consumer with initial share $\theta^{i}$ were able to choose a sequence $\left\{\tau_{t}\right\}_{t=0}^{\infty}$ at $t=0$ and once and for all (i.e., with commitment), what would her optimal choice be? The answer to this question is the solution to the problem of maximizing (3) subject to (9), (8) and the Euler equations

$$
u^{\prime}\left(c_{t}^{i}\right)=E_{t}\left[\left(1+\left(1-\tau_{t+1}\right)\left(r_{t+1}-\delta\right)\right) u^{\prime}\left(c_{t+1}^{i}\right)\right] ; \quad \forall t \geq 0, i \in[0,1]
$$

. The key observation is that $\tau_{0}$ does not enter in any constraint but (9) at $t=0$. Thus, any agent would set $\tau_{0}$ in a corner to either maximize the gain from capital taxation or minimize the loss. In particular, if $\theta^{i}<1$ we have that $\tau_{0}$ is at the upper bound, while if $\theta^{i}>1$ the initial tax is zero. Since capital is fully inelastic in the first period and completely elastic in the distant future, it is optimal to raise as much tax revenue as possible at the beginning. Concerning long-run taxes, Bassetto and Benhabib (2006) show that legislators want to minimize distortions caused by capital taxation. Taxes are generally decreasing over time and converge to zero. ${ }^{10}$

However, the optimal plan is time-inconsistent: legislators who sequentially vote on capital taxes would have the temptation to increase capital taxes every period. Potentially, in the absence of commitment this may lead to a "bad" policy outcome in which taxes are at the

\footnotetext{
${ }^{10}$ For a similar result in an economy with aggregate uncertainty and complete markets see Piguillem and Schneider (2013). Straub and Werning (2014) analyze an economy à la Judd (1985) and find that hand-tomouth consumers might favor non-zero capital taxes in the long-run.
} 
upper bound in all $t$ and savings are low. We stress that all agents with $\theta_{t}^{i}<1$ share this temptation. The lower $\theta_{t}^{i}$, the higher the temptation to raise taxes ex-post.

Equilibrium state space. In what follows, as stated in Section 3.1, we consider a state space that includes only the past tax (the status quo) and the average stock of capital. Therefore, we replace $\tilde{\mu}_{t}$ with $k_{t}$ in the functions $G$ and $\Gamma$.

Why does the state space not include the entire distribution of wealth? Since we assume that markets are incomplete and consumers cannot insure against political shocks, exact aggregation is not generally obtained. However, Krusell and Smith (1998) have shown that this type of economies exhibit approximate aggregation in the sense that using only the first moment of the distribution leads to a minimal loss of information. Further, in our economy there are no idiosyncratic shocks, only aggregate political shocks that do not change agents' ranking: as a result, the mean agent always has the average wealth. This makes additional moments even less necessary. In Appendix A.4, we show that for many arbitrary distributions the implied aggregate law of motion of capital is almost indistinguishable from the one that would arise in a representative-agent economy. Consequently, we assume that prices depend only on average capital and the status quo. ${ }^{11}$

\subsection{Legislative Bargaining}

We focus on post-election legislative bargaining and abstract from the election stage. There is a continuum of legislators with different levels of wealth. Each legislator is indexed by her current share of asset wealth $\theta \in \Theta_{L}$. Legislators' wealth shares are distributed with density $\mu^{l}(\theta)$ with support $\Theta_{L}=[\underline{\theta}, \bar{\theta}]$. We assume that legislators act in order to maximize the utility of the consumers with their same level of wealth.

In order to make our problem tractable we assume that the distribution of wealth-shares $\mu^{l}(\theta)$ in the legislature (distribution of political power) is constant over time. (Notice, however, that we are not keeping constant the distribution of legislators' asset levels, $\theta k$, because $k$ is endogenous.) In the absence of this assumption, the whole distribution of income inequal-

\footnotetext{
${ }^{11}$ The algorithm used to solve for the equilibrium is computationally demanding, because we need to compute the value functions in every state. Since we cannot assume their differentiability, we cannot use more efficient algorithms for high dimensional space, such as polynomial approximation, for which differentiability is essential. For this reason we need to use simple value function iteration. Thus, adding additional moments to "evaluate" aggregation, as in Krusell and Smith (1998), is very computationally expensive. In ongoing research we are working on a simpler environment that allows for analytical aggregation. See footnote 12.
} 
ity is a political state variable, since the current tax affects the relative wealth of legislators and, consequently, their incentives to tax in the future. It is important to emphasize that while the distribution of political power is kept constant over time, the distribution of wealthshares of consumers, $\mu(\theta)$, is completely endogenous and changes over time. Azzimonti et al. (2006) show that in the median voter model, it is enough to keep track of the assets of the mean and median agents (that is, "political" aggregation is obtained). In our model, however, every legislator can be selected to be the agenda setter. Therefore, if the distribution $\mu^{l}(\theta)$ were not constant, we would have to keep track of the entire distribution of political power. This would make our computational analysis unfeasible. In practice, as we show in Appendices A3 and A4 for the US Congress, the wealth distribution in the legislature does not resemble the one in the population. Since there is no commonly accepted theory that explains the mapping between the two distributions, we abstract from this issue and leave it for future ongoing research. ${ }^{12}$

The policy choice that is voted upon is the capital tax for the current period. Once the capital tax is selected, the lump-sum transfer is residually determined using equation (7). Let $q_{t}$ denote the current status quo. At each $t$, legislative bargaining unfolds as follows.

(i) A randomly selected member of the legislature (the agenda setter) makes a take-it-or-leave-it offer.

(ii) All legislators simultaneously cast a vote: either "yes" or "no".

(iii) Proposals pass with probability equal to the measure of legislators who vote "yes".

(iv) If the proposal is accepted, it becomes the capital tax for the current period, $\tau_{t}$, and the default option for the next period: $\tau_{t}=q_{t+1}$.

If the proposal is rejected, $q_{t}$ is implemented.

\footnotetext{
${ }^{12}$ In our economy there is only one source of uncertainty, thus inequality could potentially disappear in the long run, rendering the problem uninteresting. In order to make sure that the stationary distribution of wealth is not degenerate we would need to include an additional source of uncertainty, complicating the problem even further. We see this assumption as a reduced form of an underlying alternative source of heterogeneity that regenerates inequality. Indeed, in ongoing research we are analyzing a very different environment with idiosyncratic returns to capital and a different tax system, as in Heathcote et al. (2014). In that environment we can characterize the law of motion of the distribution. Preliminary results, which are available upon request from the authors, are qualitatively similar.
} 
As is standard in the legislative bargaining literature, we suppose that some legislators have "agenda-setting powers": they have the ability to determine which bills are considered on the floor. For instance, the chairs of important committees (such as the Rules Committee in the US House) are usually endowed with agenda-setting powers. Also, legislatures often cede agenda-setting powers to executive offices, such as the president or premier. Note that in each period only one legislator has the right to propose a tax. The identity of the agenda setter $\theta^{s}$ changes in each period and is a continuous random variable with density function $\mu^{s}\left(\theta^{s}\right)$ in the interval $[\underline{\theta}, \bar{\theta}]$. Thus, recognition probabilities are i.i.d. over time.

Point (iii) deserves some discussion. Note that acceptance is probabilistic: the higher the number of legislators that favor the proposal, the higher the probability of acceptance. This implies that proposals may be rejected even if a simple majority (over 50\%) of legislators are in favor of it. In a typical legislature, this may happen when minority legislators have the ability to delay or veto the approval of the bill. Point (iii) also implies that a proposal may pass (although with smaller probability) when it is favored by a minority in the legislature. In some other circumstances, this might be the result of vote trading across issues or party discipline. For instance, suppose that there is a party which has a majority of seats and that its policy stance is decided by the median legislator within the party. Then, if there is strict discipline within the party, a policy change may pass with the support of only 25 percent of the legislature. Acceptance is certain only when all legislators prefer the proposal to the status quo, and rejection is certain when all legislators prefer the status quo. We defend the probabilistic acceptance on two grounds. First, the assumption captures the idea that some uncertainty is inherent in the political process. In a richer model, uncertainty as to whether the bill will pass could arise when the agenda setter does not perfectly observe legislators' preferences. Second, probabilistic acceptance introduces an additional source of uncertainty to our model besides the one concerning the agenda setter's identity. The extra noise makes numerical computations more tractable.

Finally, point (iv) is the key institutional feature analyzed in this paper. It states that the current policy becomes the default option in case of disagreement in the next legislative session. This is a realistic assumption, since in most countries taxes are based on formulas written into law. Unless explicitly changed, taxes remain at the level agreed upon in the 
previous fiscal year. On this, see Tsebelis (2002, p. 8) and Rasch (2000). ${ }^{13}$

We focus on pure Markov strategies. Since strategies are stationary, the problem can be formulated in a recursive way, and in what follows we drop the time index. A proposal strategy for agenda setter $\theta^{s}$ is a function of aggregate capital $k$, and the status quo $q$ : $\tau\left(\theta^{s}\right): \Re_{+} \times[0, \bar{\tau}] \rightarrow[0, \bar{\tau}]$. After observing the proposal, legislator $\theta$ votes according to a voting rule $\alpha(\theta): \Re_{+} \times[0, \bar{\tau}] \times[0, \bar{\tau}] \rightarrow\{$ yes, no $\}$.

Given $k_{0}$, the law of motion for aggregate capital $G(k, \tau)$, the law of motion of individual $\theta$, and the equilibrium Markov process for taxes, $\Gamma(\tau \mid q, k)$, it is possible to compute $V(k, \tau, \theta)$, which denotes the value function for an individual $\theta$ who starts with assets $\theta k$ and an initial capital tax $\tau$.

As is commonly assumed in the voting literature, legislator $\theta$ supports proposal $\tau$ against the status quo if and only if $\tau$ provides higher utility than $q$. That is,

$$
\alpha(k, q, \tau ; \theta)= \begin{cases}\text { "yes" } & \text { if } \quad V(k, \tau, \theta) \geq V(k, q, \theta), \\ \text { "no" } & \text { otherwise. }\end{cases}
$$

We let $A(k, q, \tau)$ denote the set of legislators who support the proposal,

$$
A(k, q, \tau)=\left\{\theta \in \Theta_{L}: V(k, \tau, \theta) \geq V(k, q, \theta)\right\}
$$

We denote the probability that proposal $\tau$ is accepted given the pair $(k, q)$ by $\operatorname{Pr}^{a}(k, q, \tau)$. As assumed in point (iii), $\operatorname{Pr}^{a}(k, q, \tau)$ is equal to the measure of set $A(k, q, \tau)$.

$$
\operatorname{Pr}^{a}(k, q, \tau)=\left\{\begin{array}{l}
\int_{A(k, q, \tau)} \mu^{l}(\theta) d \theta \quad \text { if } \tau \neq q \\
1 \quad \text { if } \tau=q
\end{array}\right.
$$

Note that when $\tau=q$ the probability of acceptance is one. In fact, rejecting the proposal would not make any difference: the policy $q$ would be adopted regardless of the vote.

Since consumers make decisions after the legislature votes, saving decisions depend on

\footnotetext{
${ }^{13}$ For instance, the article 312 of the Treaty on the Functioning of the European Union states: "Where no Council regulation determining a new financial framework has been adopted by the end of the previous financial framework, the ceilings and other provisions corresponding to the last year of that framework shall be extended until such time as that act is adopted."
} 
current capital and on the current capital tax $\tau$. Note, however, that $\tau$ does not change the current income of the average agent. Thus, $\tau$ affects aggregate savings only because it constitutes the default option in the next legislative session.

If legislator $\theta^{s}$ is randomly chosen as the agenda setter, her optimal proposal maximizes the expected present value of utility given the current stock of capital and the current status quo:

$$
\tau\left(k, q ; \theta^{s}\right)=\arg \max _{\tau \in[0, \bar{\tau}]} \operatorname{Pr}^{a}(k, q, \tau) V\left(k, \tau, \theta^{s}\right)+\left(1-\operatorname{Pr}^{a}(k, q, \tau)\right) V\left(k, q, \theta^{s}\right)
$$

subject to

$$
k^{\prime}=G(k, \tau) ; \quad \forall \tau
$$

The first term of the objective function is the utility of implementing $\tau$ multiplied by the probability that $\tau$ is accepted. The second term is the utility of keeping the status quo, multiplied by the probability that $\tau$ is rejected. Note that this is a non-trivial problem since the agenda setter must realize the consequences of her proposal on the current and future probabilities of acceptance, on proposal rules of future agenda setters and on savings decisions.

Using the proposal rule and the probability of acceptance, the probability that each $\tau$ is implemented given a state is:

$\Gamma(\tau \mid q, k)=\left\{\begin{array}{l}\operatorname{Pr}^{a}(k, q, \tau) \int_{\tau=\tau\left(k, q ; \theta^{s}\right)} \mu^{s}\left(\theta^{s}\right) d \theta^{s} \\ \int_{q=\tau\left(k, q ; \theta^{s}\right)} \mu^{s}\left(\theta^{s}\right) d \theta^{s}+\int_{0}^{\bar{\tau}}\left(\int_{\tau^{\prime}=\tau\left(k, q ; \theta^{s}\right)}\left(1-\operatorname{Pr}^{a}\left(k, q, \tau^{\prime}\right)\right) \mu^{s}\left(\theta^{s}\right) d \theta^{s}\right) d \tau^{\prime} \text { if } \tau=q\end{array}\right.$

Expression (15) has a simple interpretation. From the first line, the probability of making a policy change to $\tau$ is equal to the measure of agenda setters that would propose $\tau$ multiplied by the probability that the proposal is accepted. The second line is the probability of maintaining the status quo. This can happen when $q$ is proposed, the first term, and when other proposals are rejected, the second term. Notice that the latter term is what explains endogenous policy persistence in the model. 
We now proceed to define the Politico-Economic Equilibrium. We require the Markov process for taxes implied by the political game to be optimal given the law of motion of aggregate capital implied by the competitive equilibrium, and vice versa.

Politico-Economic Equilibrium Definition: A politico economic equilibrium is: value functions for all legislators $V: \Re_{+} \times[0, \bar{\tau}] \times \Theta \rightarrow \Re$, proposal rules for all legislators $\tau\left(\theta^{s}\right)$ $: \Re \times[0, \bar{\tau}] \rightarrow[0, \bar{\tau}]$, voting rules for all legislators $\alpha(\theta): \Re_{+} \times[0, \bar{\tau}] \times[0, \bar{\tau}] \rightarrow\{$ yes, no $\}$, a Markov process for taxes characterized by $\Gamma(\tau \mid q, k)$, the law of motion of aggregate capital $G: \Re_{+} \times[0, \bar{\tau}] \rightarrow \Re_{+}$, laws of motion of individual capital $G(\theta): \Re_{+} \times[0, \bar{\tau}] \times \Theta \rightarrow \Re_{+}$such that

a) Given $\Gamma(\tau \mid q, k), V$ and the laws of motion of capital are generated in the competitive equilibrium.

b) Given $G(k, \tau)$ and $V$,

b.1) Voting rules satisfy (10).

b.2) The tax proposal solves problem (13).

b.3) $\Gamma(\tau \mid q, k)$ is generated by equation (15).

For more details about the algorithm used in the computations see Section 5.1 and Appendix A.1.

\section{Example}

In this section we present a simplified example to explain the mechanism behind the full dynamic model presented in Section 3. To obtain analytical solutions, we assume logarithmic utility, a linear production technology $y_{t}=A k_{t}$ and full depreciation. For all $t \geq 0$, the budget constraint of individual $i$ simplifies to

$$
c_{t}^{i}+k_{t+1}^{i}=A k_{t}^{i}\left(1-\tau_{t}\right)+T_{t}
$$

where $T_{t}=A \tau_{t} k_{t}$. 
We simplify the legislative bargaining process along the following three dimensions. First, the legislature includes two legislators, denoted by $m$ and $p$, with capital shares $\theta^{p}<\theta^{m}<1$, respectively. The assumption that both legislators are poorer than the average is not essential, and is made to emphasize that in our setting legislative bargaining disciplines politicians even when all legislators are tempted to raise taxes. As in the full model, while we assume that consumers' shares evolve over time, we suppose that legislators' shares stay constant. Second, we remove the two sources of political uncertainty that are present in our general model. We suppose that the identity of the agenda setter is fixed over time and coincides with the relatively richer legislator $\theta^{m}$. Furthermore, instead of probabilistic acceptance, we suppose that policy changes need to be approved by both legislators.

We let $\tau_{i}^{*}$ denote the constant tax that legislator $i$ would choose if she expects full political gridlock. In the Appendix, we show that $\tau_{i}^{*}$ is implicitly defined by

$$
\frac{-\left(\theta^{i}-1\right)}{1-\left(1-\tau_{i}^{*}\right) \beta}=\frac{\phi_{i} \tau_{i}^{*} \beta}{\left(1-\tau_{i}^{*}\right)(1-\beta)^{2}}
$$

where

$$
\phi_{i}=1+(1-\beta) \frac{\left(1-\tau_{i}^{*}\right)\left(\theta^{i}-1\right)}{1-\left(1-\tau_{i}^{*}\right) \beta} .
$$

The constant tax rate $\tau_{i}^{*}$ optimally solves legislator $i$ 's trade-off between the current gain of increasing taxes and long-run distortions. The higher $\theta^{i}$, the lower $\tau_{i}^{*}$. It is important to notice that in this specific example, $\tau_{i}^{*}$ does not depend on capital.

In this example, there is a simple politico-economic equilibrium.

Proposition 1 Let $q_{t} \in[0, \bar{\tau}]$ denote the status quo at time $t$. Suppose that $\theta^{p}$ is sufficiently small so that $\tau_{p}^{*}>\bar{\tau}$. There exists a PEE in which the agenda setter proposes and passes the following policy:

$$
\tau_{t}=\left\{\begin{array}{rcc}
\tau_{m}^{*} & \text { if } & q_{t}<\tau_{m}^{*} \\
q_{t} & \text { if } & \tau_{m}^{*} \leq q_{t}<\bar{\tau} .
\end{array}\right.
$$

Figure 2 illustrates the equilibrium capital tax proposed by $m$ as a function of the status quo. For status-quo policies larger than $\tau_{m}^{*}$ there is legislative gridlock: it is not possible to 
increase the utility of $m$ without decreasing the utility of $p$. As a result, no policy change is made, and the proposal lies on the 45-degree line. When, instead, the initial status quo is relatively low (namely, $q_{t} \leq \tau_{m}^{*}$ ), the agenda setter proposes $\tau_{m}^{*}$, which is passed and stays in place for all subsequent periods.

Despite the fact that both legislators have a current-period temptation to choose $\bar{\tau}$, taxes lower than $\bar{\tau}$ are sustained in equilibrium. The higher $\theta^{m}$, the lower the tax rate $\tau_{m}^{*}$ that can be sustained. Future disagreement between $p$ and $m$ creates policy persistence, which disciplines legislators. More specifically, the agenda setter internalizes that current high taxes, by changing the future status quo, will raise the bargaining power of the relatively poorer legislator. In fact, when the status quo is a high tax rate, legislator $p$ is able to keep taxes high by rejecting a tax cut. ${ }^{14}$ Knowing that the current tax will stay in place for all subsequent periods, the agenda setter has an incentive to favor $\tau_{m}^{*}$, a relatively low tax. Note that the threat of future political gridlock is credible since we assume a legislature where members represent consumers with different wealth levels. If $\theta^{p}$ and $\theta^{m}$ were identical, there would be no political gridlock, implying that low taxes cannot be sustained.

Besides the heterogeneity of preferences between $p$ and $m$, another necessary ingredient is the endogeneity of the status quo. When the default option in the bargaining process is exogenously fixed, there is no linkage across periods and the agenda setter cannot strategically affect future policy outcomes. In particular, the political cost of raising taxes at $t=0$ is null since bargaining in the future would not depend on the current policy. Therefore, the agenda setter has no incentive to keep taxes low.

Similarly, when the agenda setter can pass a proposal without the vote of the other legislator, the only equilibrium is one in which maximum taxes are always chosen. Intuitively, when legislator $m$ has all the political power, the absence of political gridlock makes the

\footnotetext{
${ }^{14}$ For the equilibrium construction, legislator $p$ must not be willing to let $m$ cut $\tau$ after a deviation to high taxes. This is the reason why in Proposition 1 we require legislator $p$ to be sufficiently poor: this guarantees that high status quos are absorbing states.
} 
agenda setter short-sighted: he procrastinates tax cuts indefinitely

Figure 2: Example: Proposal Strategy

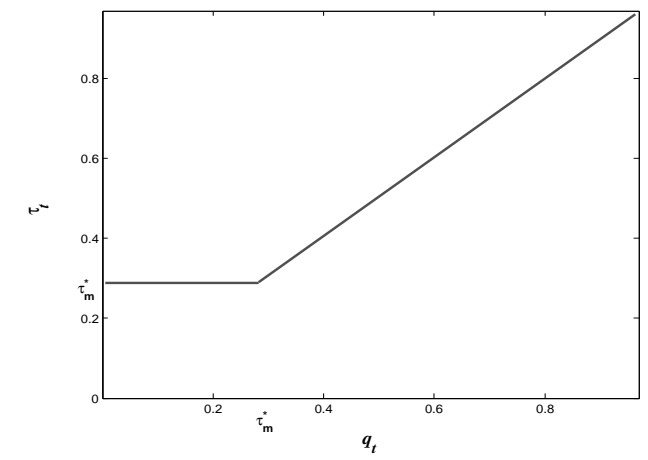

In the full model, we do not require unanimity to pass a policy change. Consequently, policy persistence will be smaller, and no status quo policy will be an absorbing state.

\section{Quantitative Exercise}

\subsection{Computational Strategy}

The numerical problem consists of solving one fixed point, the Politico-Economic Equilibrium (PEE) characterized by $\Gamma(\tau \mid q, k)$, which depends on another fixed point, the Competitive Equilibrium (CE), characterized by the law of motion of aggregate capital $G(k, \tau)$. Loosely speaking our strategy amounts to first solving the CE given $\Gamma(\tau \mid q, k)$. This generates an aggregate decision rule and new value functions. Then, we use the outputs from the CE to generate a new $\Gamma(\tau \mid q, k)$ and we repeat this procedure until convergence. In Appendix A.1, we describe the algorithm, but some details are worth mentioning.

We solve the CE using a variant of Carroll (2006)'s endogenous grid method. As we explained in Section 3.2 we solve for the law of motion of capital of a representative-agent economy. We start the iterations assuming a $G(k, \tau)$ and then apply the Carroll (2006) method to the saving problem of the average agent. Then, we set $G(k, \tau)$ equal to the saving policy function of the mean agent and repeat the procedure until the aggregate saving rule is consistent with the saving rule of the mean agent. The main difference from the solution of a standard CE problem is that fiscal policies are endogenous, thus implying that the future tax depends on the future stock of capital. This can create problems for equilibrium 
existence and convergence of numerical algorithms (when the equilibrium exists). However, as shown by Coleman (1991) and Greenwood and Huffman (1995), when the tax function is monotone increasing in the level of capital the problem disappears. We confirm in the numerical solutions that the tax function is indeed monotone increasing in the capital stock. ${ }^{15}$

To shed light on the relevance of the assumed distribution of wealth for the computation of the CE in Appendix A.4 we plot the computed law of motion of capital and compare it to the one arising from aggregating individual savings using as weights the population's distribution. We can see that both laws of motions are almost identical for most levels of aggregate capital. We have performed similar calculations with alternative distributions of net worth arriving to the same conclusion. This indicates that the wealth distribution has little or no impact for the $\mathrm{CE}$ and that all the effects of the distribution stem from the political equilibrium.

\subsection{Results}

5.2.1. Calibration. Throughout the numerical simulations we set $\beta=0.96, \alpha=0.3$ and $\delta=0.08$. We present results with two alternative calibrations for the coefficient of risk aversion, $\sigma=1$ and $\sigma=2 .{ }^{16}$ These parameters are standard in the literature. The upper bound for taxes is $\bar{\tau}=0.95$. The results are not very sensitive to it. As expected, larger values of $\bar{\tau}$ generate larger average taxes, but the effect diminishes as $\bar{\tau}$ approaches one. At $\bar{\tau}=0.95$ the change on average taxes due to further increases in $\bar{\tau}$ is negligible. Calibrating the distribution of wealth within the legislature, $\mu^{l}(\theta)$, requires making a stance on legislators' objectives. If we think that legislators are benevolent, or closely represent the population that elects them, the appropriate distribution of wealth would be the distribution of net worth in the whole population. Instead, if we think that politicians are self-interested, we should pick the distribution of wealth of the actual representatives. In what follows, we present results under two alternative calibrations.

First, we calibrate $\mu^{l}$ with the distribution of net worth in the U.S. economy using the Survey of Consumer Finances (SCF) for 2007. Since computing the acceptance probabilities

\footnotetext{
${ }^{15}$ See Figure 8. Santos, (2002) discusses the existence of Markov Equilibria in non-optimal economies. The main difference between our economy and the ones in those papers is the inclusion of the past tax as a state variable. For this reason, we cannot apply those results directly to our model.

${ }^{16}$ In the context of a Judd (1985) economy, Straub and Werning (2014) show that high values of $\sigma$ are associated with high long-run capital taxes under commitment.
} 
requires a continuous function, we approximate the observed distribution of net worth with a Frechet distribution. Under this calibration we obtain that the median share is equal to 0.25 and $\operatorname{Prob}(\theta>1)=0.20$. See Figure A.2 in the appendix for more details.

Second, we collect data from opensecrets.org and we compute the distribution of net worth for the U.S. representatives (see Appendix A.3 for more details). This data reveals that members of Congress are much richer than the population that they represent: in particular, more than $60 \%$ of the legislators are richer than the average citizen. ${ }^{17}$ In our second calibration we repeat the approximating procedure discussed above using this database instead of the SCF.

Concerning the distribution of agenda setting power, $\mu^{s}\left(\theta^{s}\right)$, in all our simulations we assume that it coincides with $\mu^{l}(\theta)$.

Before presenting the equilibrium average taxes it is informative to analyze the computed proposal and acceptance probabilities.

5.2.2. Proposal and Acceptance Strategies. The most important outputs of the numerical simulations are the proposal strategies and the acceptance probabilities. In Figure 3, we fix the level of capital and illustrate the proposed capital tax (on the vertical axis) as a function of the status quo for different values of $\theta^{s}$, the share of wealth of the recognized agenda setter. ${ }^{18}$

Three features of the proposal rules are worth noting. First, proposals are generally below the upper bound. Notice, for instance, that a proposer with share $\theta^{s}=0.77$ proposes taxes close to zero even if, when looking at the current payoff, she has an incentive to choose maximal taxes. The reason is that she realizes that setting high taxes, through a change of the status quo, would increase the future bargaining power of poorer legislators. The second and related feature is that the poorer the legislator, the higher the proposed tax for any given status quo. This is because poor legislators gain more from redistribution and consequently are more willing to accept the long run distortions associated with an increase of the status quo. For instance, note that a poor agenda setter $\left(\theta^{s}=0.26\right)$ often proposes $\bar{\tau}$, while a relatively richer agenda setter $\left(\theta^{s}=0.77\right)$ proposes much lower taxes. Third, proposal rules are monotone increasing in the status quo. For example, the upper curve in Figure 3 shows that a poor agenda setter proposes taxes lower than $\bar{\tau}$ when the initial status

\footnotetext{
${ }^{17}$ This proportion is much higher when looking at the Senate only.

${ }^{18}$ Figure 8 illustrates how proposals vary with capital, keeping fixed the status quo policy.
} 
quo is around zero, and that her proposal approaches $\bar{\tau}$ as $q$ increases. As we explain below, monotonicity of the proposal rule is a consequence of the fact that the agenda setter, in order to improve the probability of acceptance, proposes relatively small departures from the status quo (gradualism).

Figure 3: Proposal Strategies*

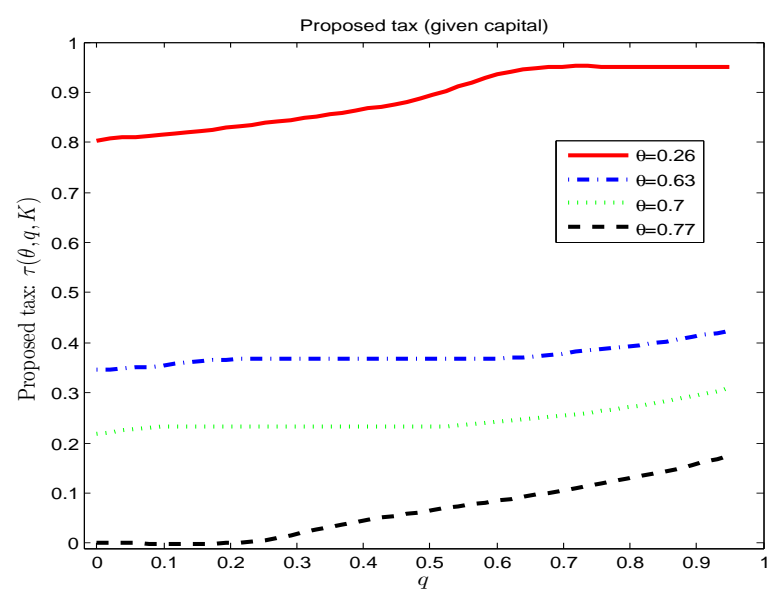

Computed with $\sigma=2$ and a legislators' distribution of wealth as in SCF 2007

The positive slope of the proposal rule is an important element of our disciplinary mechanism. It provides the channel for strategic manipulation of future agenda setters: by passing low taxes current policymakers reduce the expected proposals of future agenda setters.

It is important to emphasize that such long-run considerations would not arise in models focusing on median-voter equilibria. In those models the past tax is not payoff-relevant since the median voter is able to impose her preferred policy regardless of the policy outcome that was voted in the previous period.

Figure 4 illustrates the acceptance probabilities as a function of all possible proposals. Thus, the vertical axis measures the probability of acceptance, and the horizontal axis indicates the proposal $\tau$. As before, we compute the probability for a given level of capital. Each line in Figure 4 corresponds to a different status quo policy. Note that acceptance probabilities are below one unless the proposal coincides with the status quo, as shown in equation (12). When the proposal coincides with the status quo, legislators have no other choice than to accept the proposal. When the proposal differs from the status quo, some legislators oppose the change, which makes the probability of rejection strictly positive and 
generates the jump discontinuity at $\tau=q$. The fact that rejection occurs with positive probability creates policy persistence. Since policymakers gain from high taxes today, but they would like to commit to low taxes in the future, policy persistence attenuates the temptation to raise taxes.

Figure 4: Acceptance Probabilities*

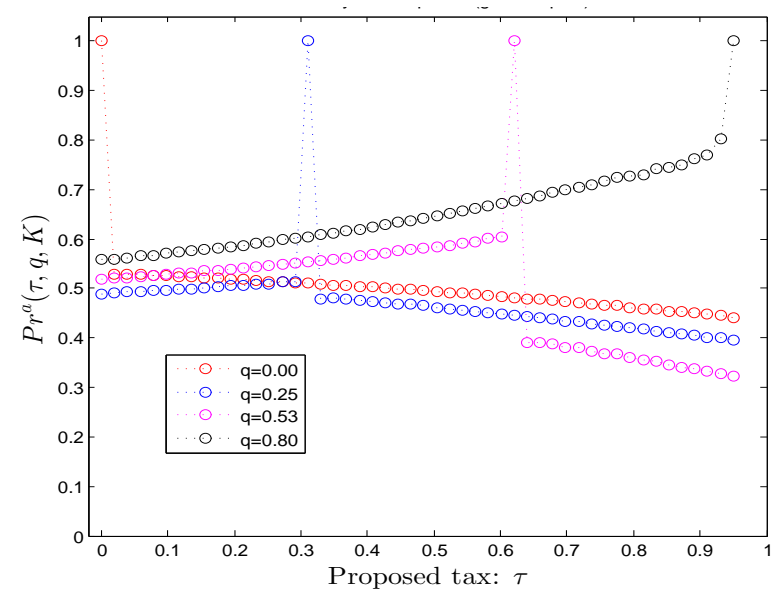

Computed assuming $\sigma=2$ and a legislators' distribution of wealth as in SCF 2007

It is worth noting that the probability of acceptance is decreasing in the distance between the status quo and the proposal. Since legislators are risk-averse, this implies gradualism in policy making. Large policy changes are less likely to be accepted because an increasing number of people are made worse off. To understand this, consider first a proposal to infinitesimally cut taxes. In this case, the legislators who oppose the change would be those who prefer a tax increase. Consider now a large tax cut and notice that the group of legislators opposing this change are not only those who prefer a tax increase, as before, but also some legislators who prefer a smaller tax cut.

Finally, note that in general there is an asymmetry between the left and the right jump from the status quo. For instance, when the status quo is 0.53 , the probability of accepting a tax increase is smaller than the probability of accepting a tax cut. This is because a tax rate of 0.53 is too high from the perspective of the majority of legislators. When instead the status quo is relatively low, the asymmetry is in the opposite direction.

5.2.3. Summary Statistics. Table 1 presents summary statistics for 10000 simulated legislative sessions. Each row corresponds to a different calibration. We present in Column 2 
the wealth share of the median legislator. In Columns 3 and 4, we show the average capital tax and the autocorrelation of the tax. In Columns 5 and 6 we report, respectively, the standard deviation of the tax and average consumption. The first two rows show that average taxes are around $50 \%$ when the distribution of wealth in the legislature coincides with the one in the population. We show results with two alternative calibrations, $\sigma=1$ and $\sigma=2$. In both cases the moments of the tax are very similar. Tax levels are well below the upper bound in spite of the fact that most legislators are poorer than the average. ${ }^{19}$

Table 1. Summary Statistics.

\begin{tabular}{lccccc}
\hline \hline Calibration & $\theta^{m}$ & $E(\tau)$ & $\operatorname{corr}\left(\tau, \tau_{-1}\right)$ & $\operatorname{std}(\tau)$ & consumption \\
\hline \hline Benevolent Legislators $(\sigma=1)$ & 0.25 & 0.51 & 0.51 & 0.39 & 0.96 \\
\hline \hline Benevolent Legislators $(\sigma=2)$ & 0.25 & 0.55 & 0.49 & 0.38 & 0.94 \\
\hline Self-interested Legislators $(\sigma=1)$ & 1.76 & 0.25 & 0.47 & 0.46 & 1.09 \\
\hline Self-interested Legislators $(\sigma=2)$ & 1.76 & 0.25 & 0.48 & 0.46 & 1.09 \\
\hline
\end{tabular}

When we assume that legislators are self-interested (using the actual distribution of wealth within the US Congress), most of the legislators are richer than the average agent in the economy. The share of the median legislator, $\theta^{m}$, increases dramatically to 1.76. Under this alternative calibration taxes are considerably lower and average consumption higher. Under the median-voter approach taxes would drop to zero when the median legislator is richer than the average. In our setting, average taxes are still positive and non-negligible. There are two reasons for this.

First, recall that recognition and acceptance probabilities reflect the entire wealth distribution. Even when we use the actual wealth distribution in the US Congress, the poor legislators' recognition probability and the acceptance probability for tax increases remain strictly positive. Second, there is an effect on equilibrium strategies. A legislator with the same wealth-share behaves differently under the two calibrations. For instance, a legislator with share $\theta=0.63$ proposes maximum taxes when she belongs to a legislature where most legislators are richer than average (Figure 5a), while she proposes more moderate taxes when

\footnotetext{
${ }^{19}$ If we assume that all legislators have a wealth-share below one, we would still obtain that average taxes are below the upper bound. Results for this calibration are shown in a previous version of this paper.
} 
she belongs to a legislature where most legislators are poorer (Figure 5b). The reason is that in a legislature with a larger proportion of poor legislators, high taxes are more persistent, which raises the cost of moving into the next period with a high status quo and increases the incentive to propose low taxes. All things being equal, a legislator becomes more disciplined when she belongs to a legislature that is eager for redistribution. Conversely, when the same legislator belongs to a Congress where most members are rich, she would have an incentive to free-ride on others' responsibility and favor higher taxes. ${ }^{20}$ Assuming a much richer legislature does not dramatically decrease taxes because the larger number of rich legislators is partially compensated by the higher taxes proposed by poorer legislators.

Figure 5a

Self-interested Legislators

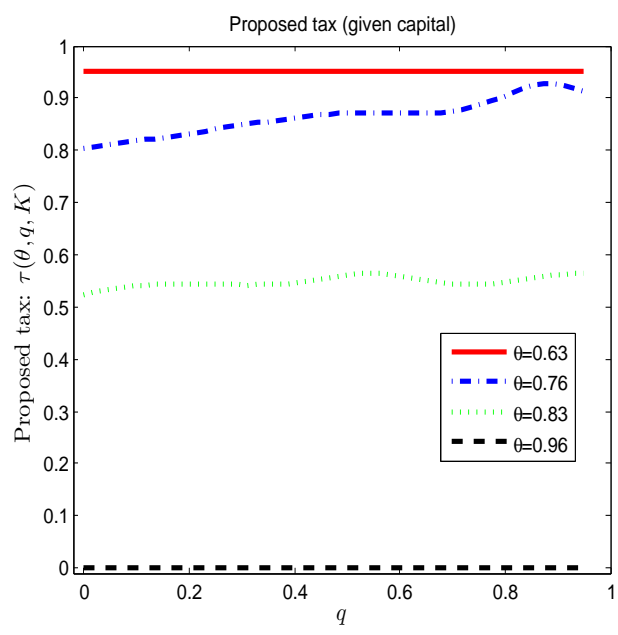

Figure 5b

Benevolent Legislators

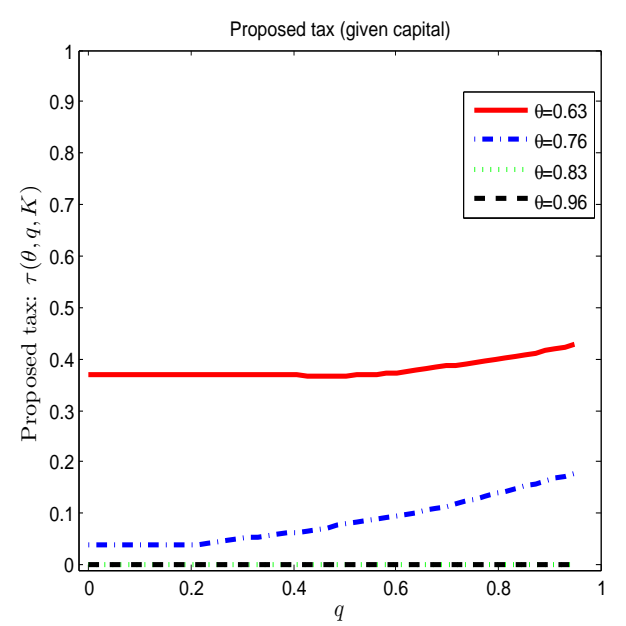

We stress from Table 1 (Column 5) that when we use the actual wealth distribution in the US Congress policies are more volatile. The increased volatility is partly explained by the higher distance between legislators' ideal points (i.e., higher polarization) shown in Figures $5 \mathrm{a}$ and 5b. With poor legislators becoming more pro-taxes, relatively richer legislators have stronger incentives to favor low taxes. A change in the legislators' wealth distribution initiates a process that feeds upon itself, leading to an amplification of the political divide. It is important to emphasize that these strategic interactions are absent from political economic models focusing on median equilibria.

\footnotetext{
${ }^{20}$ It is often suggested that voters, in order to mitigate time-consistency problems, should elect conservative legislators who are less tempted to raise taxes ex-post (see for instance Rogoff, 1985, and Persson and Tabellini, 1994b). The above discussion suggests that electing rich legislators could have unintended consequences: it raises the demand for redistribution of relatively poorer legislators.
} 
As discussed before, we keep the distribution of power fixed over time. One may conjecture that endogeneizing political power may boost the incentive to increase taxes, since reducing future legislators' inequality reduces the incentive to raise future taxes. However, with linear taxation strictly smaller than $100 \%$, the share of legislators below the average would not change, as the ranking is preserved. Further, all agents below the average, regardless of their distance to the mean, will always have the temptation to raise the current tax to the upper bound. In an simpler environment with endogenous political power, we show that politicians below the mean will not favor maximum taxes for the same reasons as in this paper (see footnote 12).

\subsubsection{Additional Legislative Restrictions.}

Figure 6: Benchmark (Left Panels) vs Two Committees (Right Panels)
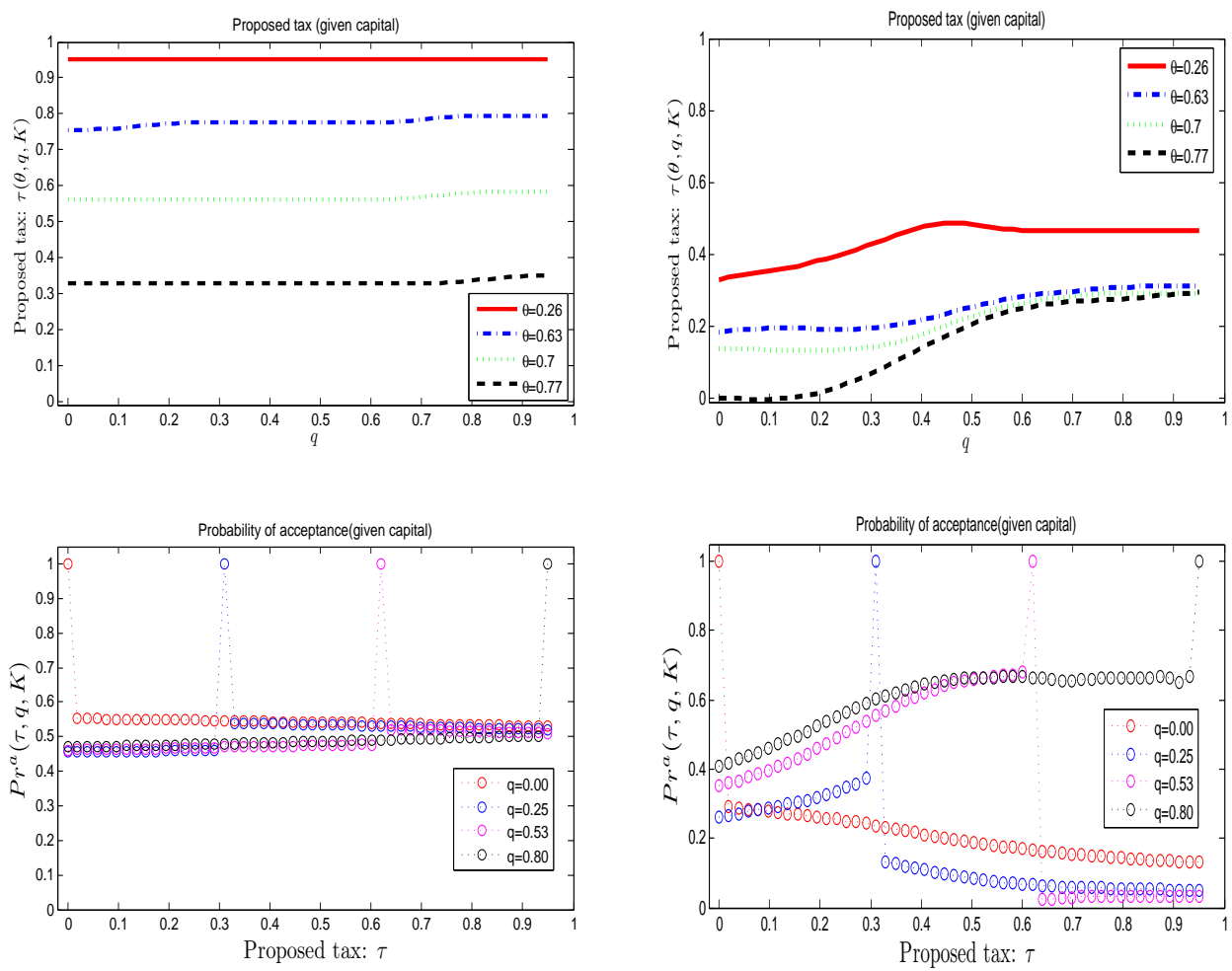

Until now we have assumed that to change the policy in place only one voting stage is required. However, in reality most policy changes require the approval of different institutional bodies. For instance, in bicameral systems changes to the tax code must be approved by the Senate and the House of representatives. Even in unicameral systems it is often the case that proposals must be approved by a committee before they can be presented to the floor. In 
order to capture the impact of these additional restrictions we assume that in order to pass, a proposal must be approved by two institutional bodies or committees. For simplicity, assume that in the two committees, legislators' wealth shares are distributed according to the same density. As before, in each committee the probability of approval is equal to the measure of legislators who prefer the policy change. Since we assume that the two votes are independent, the overall probability that the proposal passes is simply the square of expression (12). Abusing terminology, the benchmark model is called unicameral system and the alternative system is called bicameral.

Figure 6 illustrates the proposal rules (upper panels) and acceptance probabilities (lower panels) in the two systems. Equilibrium behavior under bicameralism (unicameralism) is shown in the right (left) panels. As expected, we find that the constitutional change induces more status quo bias: policy changes less likely pass in a bicameral system. ${ }^{21}$ Moreover, it affects the slope of equilibrium proposal rules. In the bicameral legislature, proposals are closer to the 45 degrees line. This is because legislators propose taxes closer to the status quo in order to increase the probability of acceptance. Finally, by increasing policy persistence, bicameralism makes it more costly to go to the next period with a high status quo. As a result, proposal rules are in general lower. By comparing results in Tables 1 and 2, note that in our stylized bicameral system taxes are lower, autocorrelation increases and public policies are less volatile.

Table 2. Bicameralism.

\begin{tabular}{lccccc}
\hline \hline Calibration & $\theta^{m}$ & $E(\tau)$ & $\operatorname{corr}\left(\tau, \tau_{-1}\right)$ & $\operatorname{std}(\tau)$ & consumption \\
\hline \hline Benevolent Legislators $(\sigma=1)$ & 0.25 & 0.34 & 0.73 & 0.32 & 1.04 \\
\hline Self-interested Legislators $(\sigma=1)$ & 1.76 & 0.12 & 0.68 & 0.41 & 1.13 \\
\hline
\end{tabular}

The high policy persistence associated to the bicameral system has important consequences for the predicted path of aggregate capital (and GDP) and taxes. Figure 7 (upper panel) illustrates a sample path for capital taxes, starting with a high status quo. Interestingly, the lower panel of Figure 7 indicates that capital evolves according to a cyclical pattern

\footnotetext{
${ }^{21}$ Notice that the equilibrium probabilities of acceptance in the bicameral system are not not exactly equal to the square of the ones under unicameralism. This is because voting rules, as described in (10), are themselves affected by the constitutional change.
} 
and that the period cycle lasts several decades.

Figure 7: Sample path: taxes and aggregate capital
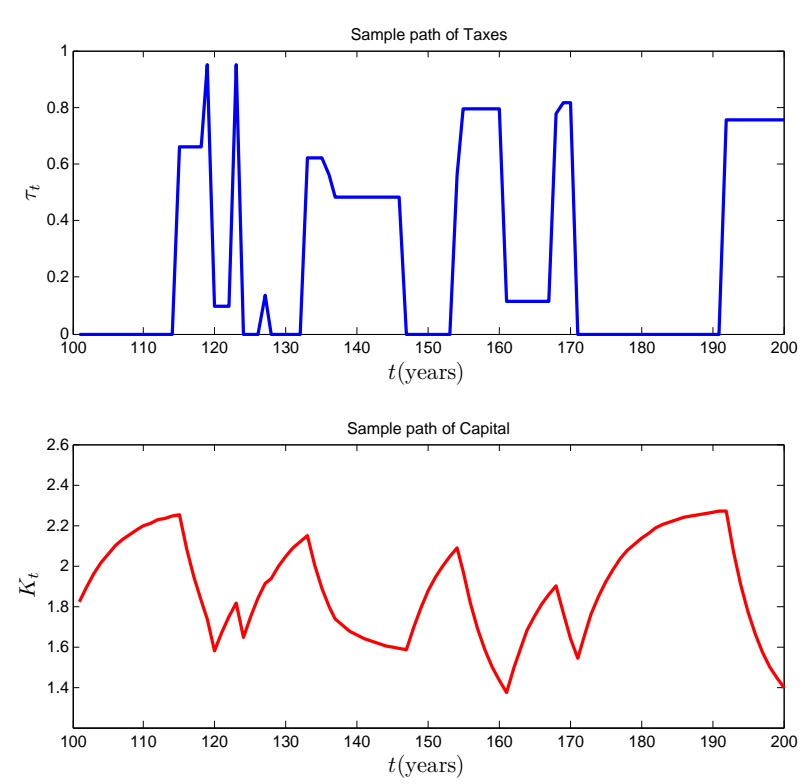

Figure 8: Expected tax and
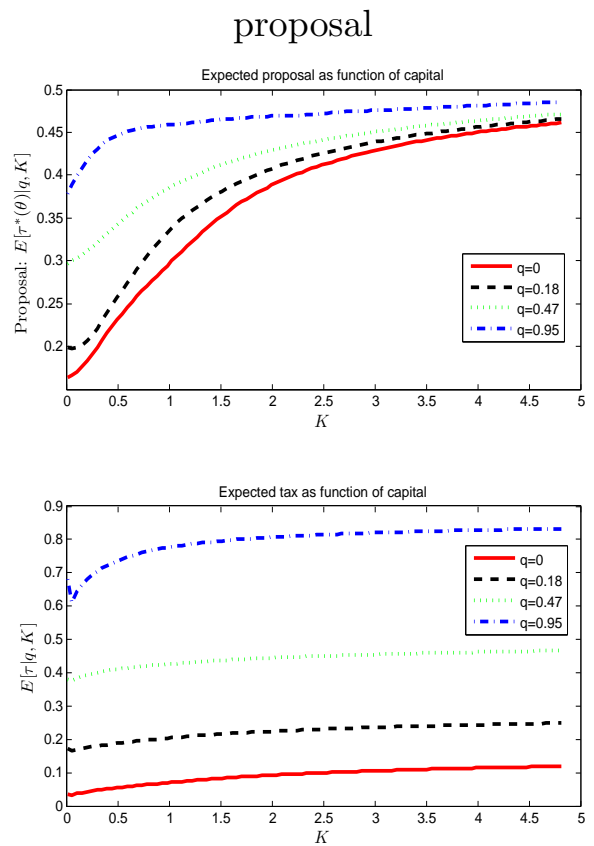

The intuition behind these "political growth cycles" is provided in Figure 8, where we show that the expected proposal (upper panel) and the expected tax (lower panel) are both monotonically increasing in current capital (represented on the horizontal axis). This feature arises because a larger capital stock increases the tax base, strengthening the temptation to raise capital taxes for redistribution purposes. Then, when capital is low, low taxes are more likely to be proposed (and pass) than high taxes. Since taxes are expected to persist, we obtain that consumers foresee several periods with low taxes and accumulate more capital. However, as the economy grows, legislators become increasingly tempted to rise taxes. Eventually, high taxes pass in the legislature, leading to a low investment rate and a reduction of the capital stock, so that the cycle begins again. ${ }^{22}$

\section{Conclusions}

We have studied a macroeconomic model where redistribution is decided in a post-election bargaining process rather than by the median voter. This point of departure from the literature is key to generate a rich set of predictions.

\footnotetext{
${ }^{22}$ Policy persistence is key to generate these cycles. In unreported results we obtained that in the unicameral system (where persistence is lower) political cycles are less pronounced.
} 
Since current capital is sunk, legislators with pre-tax income below the average have timeinconsistent indirect preferences over redistribution and taxation: they have incentives to choose maximum taxes in every period. In spite of this temptation, we find that policymakers may not propose (or accept) high capital taxes because this increases the status quo, and thus, the bargaining power of low wealth agents in the next negotiations. This future political cost is enough to generate time consistent levels of capital taxation that are reasonably low. It is worth mentioning that we obtain these results without resorting to reputational arguments or introducing ad-hoc constraints on the governments' set of choices.

The political environment and the number of checks and balances specified in the constitution are key determinants of government size. We compute average taxes under two alternative calibrations. First, we assume that the wealth distribution in the legislature coincides with the distribution of net worth in the US population and find taxes above $50 \%$. Second, we calibrate the distribution of power to match the distribution of wealth in the US Congress, which leads to lower taxes (25\%) and to more polarization. Polarization increases because adding wealthier legislators changes equilibrium behavior of poorer legislators, who have a stronger incentive to demand more redistribution. We show that endogeneizing policy making may induce political cycles: periods with low taxes and growing capital are followed by periods with high taxes and decreasing capital (and vice versa).

The economic consequences of political institutions have been studied by several authors using stylized models, often in static settings. Our paper is a first step toward understanding the effects of constitutional rules on economic outcomes in the context of a standard macroeconomic model. However, much remains to be done in order to capture more realistic features of the political and economic environment. 


\section{References}

Acemoglu, D., M. Golosov, and A. Tsyvinski (2008): "Political Economy of Mechanisms," Econometrica, 76, 619-641.

(2011): "Power Fluctuations and Political Economy," Journal of Economic Theory, 3, 1009-1041.

Aguiar, M., And M. Amador (2011): "Growth in the Shadow of Expropriation," Quarterly Journal of Economics, 126(2), 651-697.

AIYAgari, S. (1995): "Optimal Capital Income Taxation with Incomplete Markets," Journal of Political Economy, 103, 1158-75.

Alesina, A., And D. Rodrik (1994): "Distributive Politics and Economic Growth," The Quarterly Journal of Economics, 109(2), 465-90.

Alesina, A., And D. Tabellini (1990): "A Positive Theory of Fiscal Deficits and Government Debt," Review of Economic Studies, 57, 403-14.

Amador, M. (2003): "A Political Economy Model of Sovereign Debt Repayment," mimeo.

Anesi, V., and D. J. Seidmann (2015): "Bargaining in Standing Committees with an Endogenous Default," Review of Economic Studies, 82(3), 825-867.

Azzimonti, M. (2011): "Barriers to Investment in Polarized Societies," American Economic Review, 101(5), 2182-2204.

Azzimonti, M., M. Battaglini, and S. Coate (2010): "Analyzing the Case for a Balanced Budget Amendment to the U.S. Constitution," mimeo.

Azzimonti, M., E. De Francisco, and P. Krusell (2006): "Median-voter Equilibria in the Neoclassical Growth Model under Aggregation," Scandinavian Journal of Economics, 108(4), 587-606.

Azzimonti, M., And M. TAlbert (2011): "Partisan cycles and the consumption volatility puzzle," Working Papers 11-21, Federal Reserve Bank of Philadelphia. 
Bachmann, R., And J. BAI (2013): "Politico-Economic Inequality and the Comovement of Government Purchases," Review of Economic Dynamics, 16(4), 565-580.

Baron, D. (1996): "A Dynamic Theory of Collective Goods Programs," American Political Science Review, 90, 316-330.

Baron, D., And R. Bowen (2013): "Dynamic Coalitions," Stanford University, mimeo.

Baron, D., And J. Ferejohn (1989): "Bargaining in Legislatures," American Political Science Review, 83(4), 1181-1206.

Baron, D., And M. Herron (2003): "A Dynamic Model of Multidimensional Collective Choice," Computational Models in Political Economy, pp. 13-47.

Barseghyan, L., M. Battaglini, and S. Coate (2013): "Fiscal policy over the real business cycle: A positive theory," Journal of Economic Theory, 148(6), 2223-2265.

Bassetto, M. (2008): "Political Economy of Taxation in an Overlapping-Generation Model," Review of Economic Dynamics, 1, 18-43.

Bassetto, M., and J. BenhabiB (2006): "Redistribution, Taxes, and the Median Voter," Review of Economic Dynamics, 9, 211-223.

Battaglini, M., and S. Coate (2007): "Inefficiency in Legislative Policy-making: a Dynamic Analysis," American Economic Review, 97(1), 118-49.

- (2008): "A dynamic theory of public spending, taxation and debt," American Economic Review, 98(1), 201-36.

BÉnABOU, R. (1996): Inequality and Growth. NBER Macroeconomics Annual, Ben Bernanke and Julio Rotemberg eds. MIT Press.

BÉnabou, R., And E. A. OK (2001): "Social Mobility And The Demand For Redistribution: The Poum Hypothesis," The Quarterly Journal of Economics, 116(2), 447-487.

Bernheim, D., A. Rangel, and L. Rayo (2006): "The Power of the Last Word in Legislative Policy Making," Econometrica, 74(5), 1161-1190. 
Bisin, A., A. Lizzeri, And L. Yariv (2015): "Government Policy with Time Inconsistent Voters," American Economic Review, 105(6), 1711-37.

Bowen, R., Y. Chen, and H. Eraslan (2014): "Mandatory Versus Discretionary Spending: the Status Quo Effect," American Economic Review, 104(10), 2941-74.

Bowen, R., and Z. Zahran (2012): "On Dynamic Compromise," Games and Economic Behavior, 76, 391-419.

Carroll, C. (2006): "The Method of Endogenous Gridpoints for Solving Dynamic Stochastic Optimization Problems," Economics Letters, 91(3), 312-320.

Chamley, C. (1986): "Optimal Taxation of Capital Income in General Equilibrium with Infinite Lives," Econometrica, 54(3), 607-22.

Chari, V., And P. Kehoe (1990): "Optimal Taxation of Capital Income in General Equilibrium with Infinite Lives," Journal of Political Economy, 98(4), 783-802.

Coleman, W. I. (1991): "Equilibrium in a Production Economy with an Income Tax," Econometrica, 59(4), 1091-1104.

Conesa, J., S. Kitao, and B. Krueger (2009): "Taxing Capital? Not a Bad Idea after All!," American Economic Review, 99(1), 25-48.

Corbae, D., P. D'Erasmo, and B. Kuruscu (2009): "Politico-economic consequences of rising wage inequality," Journal of Monetary Economics, 56(1), 1-36.

Debortoli, D., and R. Nunes (2010): "Fiscal policy under loose commitment," Journal of Economic Theory, 145(3), 1005-1032.

Diermeier, D., And P. Fong (2011): "Legislative Bargaining with Reconsideration," The Quarterly Journal of Economics, 126(2), 947-985.

Duggan, J., and T. Kalandrakis (2011): "A Newton Collocation Method for Solving Dynamic Bargaining Games," Social Choice and Welfare, 36(3), 611-650.

Dziuda, W., And A. Loeper (2015): "Dynamic Collective Choice with Endogenous Status Quo," forthcoming Journal of Political Economy. 
Greenwood, J., and W. Huffman (1995): "On the existence of Non-Optimal Equilibria in Dynamic Stochastic Economies," Journal Of Economic Theory, 65(2), 611-623.

Heathcote, J., K. Storesletten, and G. L. Violante (2014): "Optimal Tax Progressivity: An Analytical Framework," Staff Report 496, Federal Reserve Bank of Minneapolis.

Judd, K. (1985): "Redistributive Taxation in a Simple Perfect Foresight Model," Journal of Public Economics, 28(1), 59-83.

Kalandrakis, T. (2004): "A Three-player Dynamic Majoritarian Bargaining Game," Journal of Economic Theory, 116(2), 294-322.

Klein, P., P. Krusell, and J. Ríos-Rull (2008): "Time Consistent Public Policy," Review of Economic Studies, 75(3), 789-808.

Klein, P., And J. Ríos-Rull (2003): "Time Consistent Optimal Fiscal Policy," International Economic Review, 44(4), 1217-1245.

Krusell, P., V. Quadrini, and J. Ríos-Rull (1997): "Politico-economic Equilibrium and Economic Growth," Journal of Economic Dynamics and Control, 21(1), 243-272.

Krusell, P., and J. Ríos-Rull (1999): "On the Size of U.S. Government: Political Economy in the Neoclassical Growth Model," American Economic Review, 89(5), 11561181.

Krusell, P., And A. A. Smith (1998): "Income and Wealth Heterogeneity in the Macroeconomy," Journal of Political Economy, 106(5), 867-896.

Lizzeri, A., And L. YARIV (2015): "Collective Self Control," CEPR Discussion Papers 10458, C.E.P.R. Discussion Papers.

Martin, F. (2010): "Markov-Perfect Capital and Labor Taxes," Journal of Economic Dynamics and Control, 34(3), 503-521.

Meltzer, A., And F. Richard (1982): "A Rational Theory of the Size of Government," Journal of Political Economy, 89(5), 914-27.

Nunnari, S. (2012): "Legislative Bargaining with Veto Power," mimeo. 
Perotti, P. (1996): "Growth, Income Distribution and Democracy: What the Data Say," Journal of Economic Growth, 1(2), 14987.

Persson, T., G. Roland, and G. Tabellini (1997): "Separation of Powers and Political Accountability," Quarterly Journal of Economics, 112(4), 1163-1202.

(2000): "Comparative Politics and Public Finance," Journal of Political Economy, 108(6), 1121-1161.

Persson, T., And L. Svensson (1989): "Why a Stubborn Conservative Would Run a Deficit : Policy with Time-inconsistency Preferences," Quarterly Journal of Economics, $104(2), 325-45$.

Persson, T., and G. Tabellini (1994a): "Is Inequality Harmful for Growth?," American Economic Review, 84(3), 600-21.

L (1994b): "Representative democracy and capital taxation," Journal of Public Economics, 55(1), 5370 .

(2003): The Economic Effects of Constitutions. MIT Press.

Phelan, C., And E. Stacchetti (2001): "Sequential Equilibria in a Ramsey Tax Model," Econometrica, 69(6), 1491-1518.

Piguillem, F., And A. Riboni (2015): "Spending-Biased Legislators: Discipline Through Disagreement," The Quarterly Journal of Economics, 130(2), 901-949.

Piguillem, F., And A. Schneider (2013): "Heterogeneous Labor Skills, the Median Voter and Labor Taxes," Review of Economics Dynamics, 16(2), 332-349.

Piketty, R., And E. SAez (2012): "A Theory of Optimal Capital Taxation," NBER Working Paper No. 17989.

RAsch, B. (2000): "Parliamentary Floor Voting Procedures and Agenda Setting in Europe," Legislative Studies Quarterly, 25(1), 3-23.

Riboni, A. (2010): "Committees as Substitutes for Commitment," International Economic Review, 51(1), 213-236. 
Riboni, A., and F. Ruge-Murcia (2008): "The Dynamic (In)efficiency of Monetary Policy by Committee," Journal of Money, Credit and Banking, 40(5), 1001-1032.

Rogoff, K. (1985): "The Optimal Degree of Commitment to an Intermediate Monetary Target," The Quarterly Journal of Economics, 100(4), 1169-89.

Romer, T., And H. Rosenthal (1978): "Political Resource Allocation, Controlled Agendas, and the Status Quo," Public Choice, 33(4), 27-44.

Santos, M. (2002): "On Non-existence of Markov Equilibria in Competitive Market Economies," Journal of Economic Theory, 105(1), 73-98.

Straub, L., And I. Werning (2014): "Positive Long Run Capital Taxation: ChamleyJudd Revisited," NBER Working Papers 20441, National Bureau of Economic Research, Inc.

Tsebelis, G. (2002): Veto Players: How Political Institutions Work. Princeton University Press.

YARed, P. (2010): "Politicians, Taxes and Debt," Review of Economic Studies, 77(2), 806840. 


\section{Appendix}

\section{A.1. Algorithm}

Given a measure $\mu^{s}$ of agenda setters and $\mu^{l}$ of legislators, construct grids $\mathcal{K}, \mathcal{T}$, and $\Theta$ for, respectively:

1. Capital stock $k \in\left[k_{\min }, k_{\max }\right]$.

2. $\operatorname{Tax} \tau \in[0, \bar{\tau}]$.

3. Share of average capital $\theta \in\left[0, \theta_{\max }\right]$.

Remarks. The convergency and robustness of the numerical results are not sensitive to the sizes of the grid for $k$ and $\tau$. In contrast, if the grid for $\theta$ is not fine enough the algorithm may fail to converge. In particular, the tolerance for convergency must be adjusted to the coarseness of the grid.

Guess an initial Markov process for taxes $\Gamma_{0}(\tau \mid q, k): \mathcal{T} \times \mathcal{T} \times \mathcal{K} \rightarrow[0,1]$ and an initial law of motion of aggregate capital $G_{0}(k, \tau): \mathcal{T} \times \mathcal{K} \rightarrow \mathcal{K}$. We pin down the competitive equilibrium with persistence by starting the simulations with $\Gamma_{0}(\tau \mid \tau, k)=1$ for all $k, \tau$. See Section 4 for a discussion about this choice. Further, in order to preserve the persistence of the transition function we assume that with some probability $\pi_{i}$ (where the index $i$ denotes the iteration) the legislature makes no decision and the current status quo stays in place. We let $\pi_{i}$ go to zero as the number of iterations increases. Thus, at the solution it is always the case that $\pi_{i}=0$. This transitory exogenous positive probability of staying in the status quo makes the convergency toward the equilibrium more stable.

Fix the tolerance level for the political game, $\epsilon>0$ and $\pi_{0}>0$.

Step 1 (Solve Competitive Equilibrium) Given $\Gamma_{0}$ solve for the equilibrium law of motion for capital: $k^{\prime}=$ $G(k, \tau)$ for $(k, \tau) \in \mathcal{K} \times \mathcal{T}$, using the endogenous grid method of Carroll (2006).

Starting for a given $G_{0}(k, \tau)$ solve the optimal decision of the average agent, which delivers an individual policy function $g(k, \tau)$. Then, replace $G_{0}(k, \tau)$ with $g(k, \tau)$ and solve for a new individual policy function. Iterate until convergency. Since the fixed grid is $\mathcal{K}$, the output from this step would be the matrix $k_{0} \in \Re^{2}$ such that $k=\widetilde{G}_{1}\left(k_{0}, \tau\right)$ for all $(k, \tau) \in \mathcal{K} \times \mathcal{T}$. Using linear interpolation we obtain the mapping $G_{1}: \mathcal{K} \times \mathcal{T} \rightarrow \Re$.

Let $d_{G}=\operatorname{norm}\left(G_{0}-G_{1}\right)$.

We update $G_{0}=\alpha G_{1}+(1-\alpha) G_{0}$ for some $\alpha \in(0,1)$. We use values of $\alpha$ between 0.8 and 0.9 . This slow updating avoids overshooting of the transition matrix for taxes.

Step 2 (Compute value functions) Given $\Gamma_{0}$ and $G_{0}$ compute the value function for each agent, $V(k, \tau, \theta)$, using the standard iteration of the value function (starting with $V(k, \tau, 1)=\theta$ ) and interpolating for values of $k$ outside the grid. 
Step 3 (Update Markov process for taxes) Using equation (11) we compute, for each $k$ and $q$, the set of legislators who prefer a new policy $\tau$ to the status quo $q$. Then, the probability of acceptance of a tax $\tau$ given status quo $q$ and capital stock $k$, is given by (12). In addition, given the acceptance probability, $V(k, \tau, \theta)$ and $G_{0}(k, \tau)$ we can compute the optimal choice for each agenda setter using equation (13) and obtain $\tau(k, \tau, \theta)$. Since we are not certain about the properties of the objective function we use a global method to choose the maximum. That is, we evaluate the objective function for all possible combinations of $k$ and $\tau$ and choose the maximum value.

Both $\operatorname{Pr}^{a}(k, q, \tau)$ and $\tau(k, \tau, \theta)$ then imply a new Markov process for taxes using a modified version of (15) as follows:

$$
\Gamma_{1}(\tau \mid q, k)= \begin{cases}\left(1-\pi_{i}\right) \operatorname{Pr}^{a}(k, q, \tau) \int_{\tau=\tau\left(k, q ; \theta^{s}\right)} \mu^{s}\left(\theta^{s}\right) d \theta^{s} & \text { if } \tau \neq q \\ \left(1-\pi_{i}\right)\left[\int_{q=\tau\left(k, q ; \theta^{s}\right)} \mu^{s}\left(\theta^{s}\right) d \theta^{s}+\int_{0}^{\bar{\tau}}\left(\int_{\tau^{\prime}=\tau\left(k, q ; \theta^{s}\right)}\left(1-P r^{a}\left(k, q, \tau^{\prime}\right)\right) \mu^{s}\left(\theta^{s}\right) d \theta^{s}\right) d \tau^{\prime}\right]+\pi_{i} \text { if } \tau=q\end{cases}
$$

Step 4 (Updating) Check the distance between the assumed process for taxes and that implied by the policy game. Define $d_{\Gamma}=\operatorname{norm}\left(\Gamma_{0}-\Gamma_{1}\right)$.

If $\max \left(d_{G}, d_{\Gamma}\right)<\epsilon$ and $\pi_{i}=0$ stop: the equilibrium has been found. Otherwise go to Step 1, updating $\Gamma_{0}$ with $\alpha \Gamma_{1}+(1-\alpha) \Gamma_{0}$ for some $\alpha \in(0,1)$ and $\pi_{i+1}=\max \left\{\pi_{0}\left(n_{\pi}-i\right) / n_{\pi}, 0\right\}$, where $n_{p i}<\max$ number of iterations makes sure that $\pi_{i}$ is eventually zero.

\section{A.2. Example}

Lemma 1 Consider an arbitrary $t \geq 0$. Let $\left(\tau_{t}, \tau_{t+1}, \tau_{t+2}, ..\right)$ denote the expected tax sequence from $t$ onwards. For all subsequent $t$, agent $i$ 's consumption is a constant fraction $\phi_{i}$ of average, with

$$
\phi_{i}=1+\frac{(1-\beta)\left(k_{t}^{i}-k_{t}\right)\left(1-\tau_{t}\right) r_{t}}{c_{t}}
$$

Proof of Lemma 1. Without any loss of generality, suppose $t=0$. One can write the intertemporal budget constraint as follows:

$$
\sum_{t=0}^{\infty} \beta^{t} c_{t}^{i} \varphi_{t}=k_{0}^{i}+\sum_{t=0}^{\infty} T_{t} \beta^{t} \varphi_{t}
$$

where

$$
\varphi_{t}=\frac{1}{\beta^{t}} \prod_{s=0}^{t} \frac{1}{\left(1-\tau_{s}\right) A}
$$

The Euler equation for consumer $i$ is

$$
\frac{1}{c_{0}^{i}}=\frac{\left(1-\tau_{0}\right) A}{\varphi_{t}} \frac{1}{c_{t}^{i}}
$$


while the Euler equation for the average consumer is

$$
\frac{1}{c_{0}}=\frac{\left(1-\tau_{0}\right) r_{0}}{\varphi_{t}} \frac{1}{c_{t}}
$$

Then for all $t \geq 0$

$$
c_{t}^{i}=\phi_{i} c_{t}
$$

We rewrite the intertemporal budget constraint of consumer $i$ as

$$
\sum_{t=0}^{\infty} \beta^{t} \phi_{i} c_{t} \varphi_{t}=k_{0}^{i}+\sum_{t=0}^{\infty} T_{t} \beta^{t} \varphi_{t}
$$

while the one for the average consumer is

$$
\sum_{t=0}^{\infty} \beta^{t} c_{t} \varphi_{t}=k_{0}+\sum_{t=0}^{\infty} T_{t} \beta^{t} \varphi_{t}
$$

Subtract (A.7) and (A.8) and obtain

$$
\sum_{t=0}^{\infty} \beta^{t}\left(\phi_{i}-1\right) c_{t} \varphi_{t}=k_{0}^{i}-k_{0}
$$

Use the euler equation of the average consumer, equation (A.5), to obtain

$$
\phi_{i}=1+\frac{(1-\beta)\left(\theta_{0}^{i}-1\right) k_{0}\left(1-\tau_{0}\right)}{k_{0}\left(1-\beta\left(1-\tau_{1}\right)\right)}
$$

Consider a tax path $\tau^{t}=(\tilde{\tau}, \tau, \tau, \tau \ldots)$ in which taxes are constant from tomorrow onwards. The current tax is $\tilde{\tau}$. It is easy to show that the law of motion of aggregate capital does not depend on $\tilde{\tau}$, but only on $\tau$. Aggregate capital evolves as

We denote by $\tau^{t}$ any tax sequence $\left(\tau^{\prime}, \tau, \tau, \tau \ldots\right)$ for an arbitrary $\tau^{\prime}$ and $\tau$. Given the tax sequence $\boldsymbol{\tau}^{t}=\left(\tau^{\prime}, \tau, \tau, \tau \ldots\right)$., after standard algebra we obtain that the value function at time $t$ for an individual with share $\theta_{t}^{i}$ is

$$
V\left(k_{t}, \theta_{t}^{i} ; \boldsymbol{\tau}^{t}\right)=\frac{\log \left(\phi_{i}\left(\boldsymbol{\tau}^{t}, \theta_{t}^{i}\right)\right)}{1-\beta}+V\left(k_{1}, 1 ; \boldsymbol{\tau}^{t}\right)
$$

where

$$
V_{1}\left(k_{t}, 1 ; \boldsymbol{\tau}^{t}\right)=\frac{\log \left(A k_{t}\right)}{1-\beta}+\frac{1}{1-\beta}\left[\log (1-(1-\tau) A \beta)+\frac{\beta \log ((1-\tau) \beta)}{1-\beta}\right]
$$

and

$$
\phi_{i}\left(\boldsymbol{\tau}^{t}, \theta_{t}^{i}\right)=1+(1-\beta) \frac{\left(1-\tau^{\prime}\right)\left(\theta_{t}^{i}-1\right)}{1-(1-\tau) \beta}
$$


Proof of Proposition 1. Let $q_{t}$ be any feasible status quo. We need to show that there are no profitable one-shot deviations.

Let $\tau_{t}^{\prime}$ denote the deviation from the posited equilibrium at time $t$. In the continuation game after the deviation, we use (19) to find out the policies off-equilibrium. Two cases must be considered. First, $q_{t} \in\left[\tau_{m}^{*}, \bar{\tau}\right]$. Second $q_{t} \in\left[0, \tau_{m}^{*}\right)$

Case 1. Suppose the current status quo is above the threshold $\tau_{m}^{*}$. That is, $q_{t} \in\left[\tau_{m}^{*}, \bar{\tau}\right]$. First we show that a one-shot deviation $\tau_{t}^{\prime}>q_{t}$ would not be profitable for $m$ as the legislature would permanently move to $\tau_{t}^{\prime}$. In fact, it is easy to verify that the constant tax $\tau$ which maximizes legislator's $m$ value function $V\left(k_{t}, \theta_{m}\right)$ is $\tau_{m}^{*}$. Moreover, $m$ 's value function is single-peaked in the constant tax. Therefore, from $m$ 's perspective, staying permanently in $q_{t}$ is preferable than permanently moving to the higher tax $\tau_{t}^{\prime}$. Second, consider a one-shot deviation $\tau_{m}^{*}<\tau_{t}^{\prime}<q_{t}$. Following a similar argument, it is immediate that such deviation would be profitable for $m$, but would be rejected by $p$. Third, and finally, suppose that $\tau_{t}^{\prime}<\tau_{m}^{*}<q_{t}$.

It is possible to show that such deviation would not be profitable for $p$. Legislator $p$ compares the following two vectors $\left[\tau_{t}^{\prime}, \tau_{m}^{*}, \tau_{m}^{*}, ..\right]$ to $\left[q_{t}, q_{t}, q_{t}, ..\right]$. To prove that the deviation is not profitable, we follow two steps. First, it is immediate to show that $p$ prefers $\left[q_{t}, q_{t}, q_{t}, ..\right]$ to $\left[\tau_{m}^{*}, \tau_{m}^{*}, \tau_{m}^{*}, ..\right]$. Second, it is possible to prove that legislator $p$ prefers $\boldsymbol{\tau}_{m}^{*}=\left[\tau_{m}^{*}, \tau_{m}^{*}, \tau_{m}^{*}, ..\right]$ to $\boldsymbol{\tau}^{\prime}=\left[\tau_{t}^{\prime}, \tau_{m}^{*}, \tau_{m}^{*}, ..\right]$ if

$$
\begin{aligned}
& \frac{1}{1-\beta} \log \left(1+(1-\beta) \frac{\left(1-\tau_{m}^{*}\right)\left(\theta_{p}-1\right)}{1-\left(1-\tau_{m}^{*}\right) \beta},\right)+V_{1}\left(\boldsymbol{\tau}_{m}^{*}, k_{t}, 1\right) \\
\geq & \frac{1}{1-\beta} \log \left(1+(1-\beta) \frac{\left(1-\tau_{t}^{\prime}\right)\left(\theta_{p}-1\right)}{1-\left(1-\tau_{m}^{*}\right) \beta},\right)+V_{1}\left(\boldsymbol{\tau}^{\prime}, k_{t}, 1\right)
\end{aligned}
$$

where $V_{1}\left(\boldsymbol{\tau}_{m}^{*}, k_{t}, 1\right)$ is the value function of the average consumer. First, notice that $V_{1}\left(\boldsymbol{\tau}_{m}^{*}, k_{t}, 1\right)=$ $V_{1}\left(\boldsymbol{\tau}^{\prime}, k_{t}, 1\right)$ as time-t tax does not affect consumption at time $\mathrm{t}$ for the average consumer and saving behavior is identical under the two tax sequences $\boldsymbol{\tau}_{m}^{*}$ and $\boldsymbol{\tau}^{\prime}$. Since $\theta_{p}<1$ and $\tau_{m}^{*}>\tau_{t}^{\prime}$, it follows that (A.13) holds. Therefore, legislator $p$ prefers $\left[q_{t}, q_{t}, q_{t}, ..\right]$ to $\left[\tau_{t}^{\prime}, \tau_{m}^{*}, \tau_{m}^{*}, ..\right]$.

We have therefore shown that when the current status quo is above the threshold $\tau_{m}^{*}$, there are no feasible deviations which are profitable.

Case 2. Suppose the current status quo is below the threshold $\tau_{m}^{*}$. That is, $q_{t} \in\left[0, \tau_{m}^{*}\right]$. In this case, $p$ is expected to propose $\tau_{m}^{*}$. First we show that a one-shot deviation $\tau_{t}^{\prime}>\tau_{m}^{*}$ would not be profitable for $m$ as the legislature would permanently move to $\tau_{t}^{\prime}$. We know in fact that 
from $m$ 's perspective, staying permanently in $\tau_{m}^{*}$ is preferable than permanently moving to any tax higher than $\tau_{m}^{*}$. Second, consider a one-shot deviation $0 \leq \tau_{t}^{\prime}<\tau_{m}^{*}$. In the continuation game, the legislature will move to $\tau_{m}^{*}$. Agenda setter $p$ is therefore comparing the following two vectors $\boldsymbol{\tau}^{\prime}=\left[\tau_{t}^{\prime}, \tau_{m}^{*}, \tau_{m}^{*}, ..\right]$ to $\boldsymbol{\tau}_{m}^{*}=\left[\tau_{m}^{*}, \tau_{m}^{*}, \tau_{m}^{*}, ..\right]$. Such deviation is profitable if

$$
\begin{aligned}
& \frac{1}{1-\beta} \log \left(1+(1-\beta) \frac{\left(1-\tau_{t}^{\prime}\right)\left(\theta_{m}-1\right)}{1-\left(1-\tau_{m}^{*}\right) \beta},\right)+V_{1}\left(\boldsymbol{\tau}^{\prime}, k_{t}, 1\right) \\
> & \frac{1}{1-\beta} \log \left(1+(1-\beta) \frac{\left(1-\tau_{m}^{*}\right)\left(\theta_{m}-1\right)}{1-\left(1-\tau_{m}^{*}\right) \beta},\right)+V_{1}\left(\boldsymbol{\tau}_{m}^{*}, k_{t}, 1\right)
\end{aligned}
$$

Since $\theta_{m}<1$ and $\tau_{m}^{*}>\tau_{t}^{\prime}$, it follows that (A.14) does not hold. Therefore, legislator $p$ does not find it profitable to delay the move to $\tau_{m}^{*}$.

\section{A.3. Distribution of net worth}

\section{Distribution of Net worth in the population}

Figure A.2: Kernel Density and Frechet approximation.

Distribution of Net worth SCF 2007
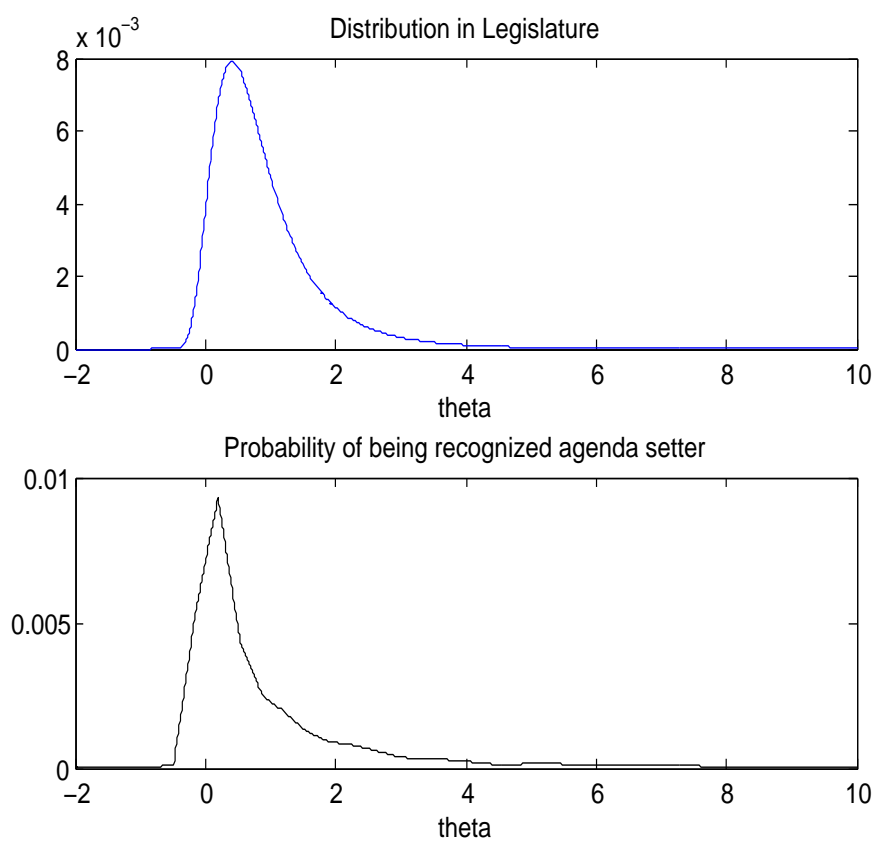


\section{Distribution of Legislators' net worth}

Figure A.3: kernel density distribution of Net worth. Members of US Congress

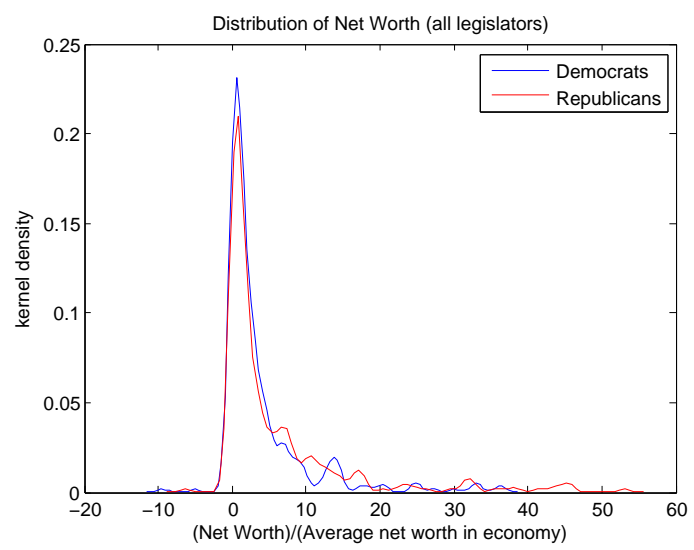

Table A.1: net worth for the U.S. members of Congress

\begin{tabular}{|l|rrr|}
\hline & Democrats & \multicolumn{3}{c|}{$\begin{array}{c}\text { Rummary } \\
\text { Republicans }\end{array}$} & Difference (\%) \\
\hline House & $4,488,893$ & $7,561,302$ & $68 \%$ \\
Average & 654,006 & 848,035 & $30 \%$ \\
Median & 0.58 & 0.61 & $-63 \%$ \\
Prop richer than average & & & $17 \%$ \\
\hline Senate & $19,383,524$ & $7,153,985$ & \\
Average & $2,579,507$ & $3,025,002$ & \\
Median & 0.85 & 0.83 & $21 \%$ \\
Prop richer than average & & & \\
\hline Boths Chambers together & $7,209,600$ & $7,491,000$ & \\
Average & 891,506 & $1,075,002$ & 0.65 \\
Median & 0.63 & & \\
Prop richer than average & & & \\
\hline
\end{tabular}




\section{A.4. Precision of forecasted prices}

Figure A.4: Compare Implied vs. guessed interest rate

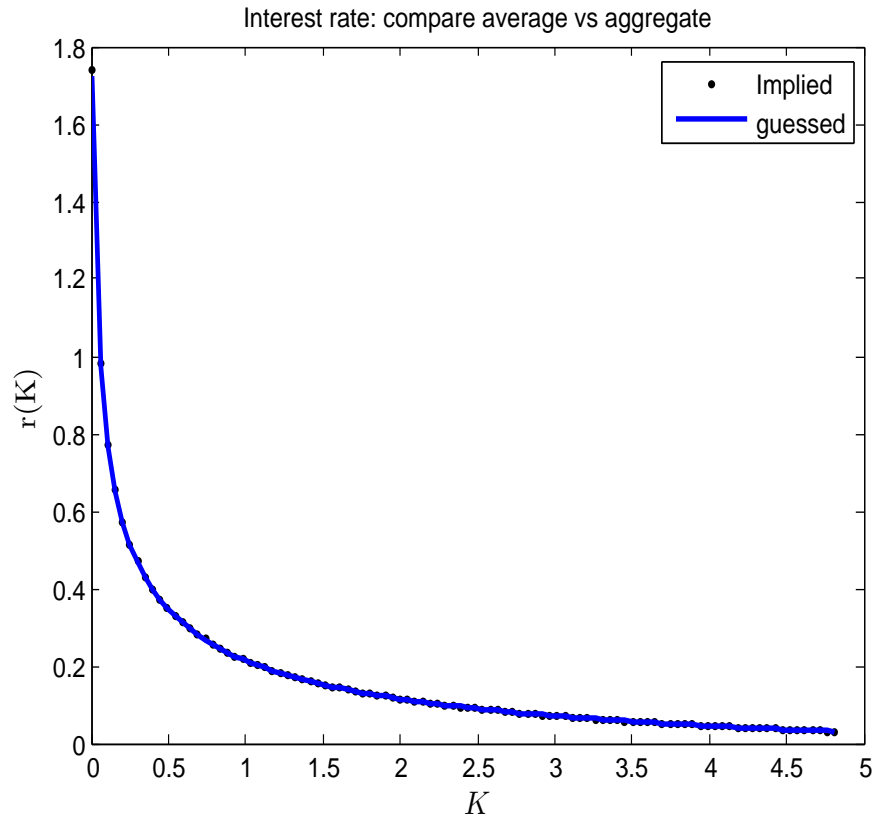

